\title{
Roles of circRNAs in the tumour microenvironment
}

\author{
Qiuge Zhang ${ }^{2,3}$, Weiwei Wang ${ }^{4}$, Quanbo Zhou ${ }^{1}$, Chen Chen ${ }^{1,3}$, Weitang Yuan ${ }^{1}$, Jinbo Liu ${ }^{1 *}$, Xiaoli Li ${ }^{2 *}$ \\ and Zhenqiang Sun ${ }^{1,3^{*}}$
}

\begin{abstract}
The tumour microenvironment (TME) constitutes the area surrounding the tumour during its development and has been demonstrated to play roles in cancer-related diseases through crosstalk with tumour cells. Circular RNAs (circRNAs) are a subpopulation of endogenous noncoding RNAs (ncRNAs) that are ubiquitously expressed in eukaryotes and have multiple biological functions in the regulation of cancer onset and progression. An increasing number of studies have shown that circRNAs participate in the multifaceted biological regulation of the TME. However, details on the mechanisms involved have remained elusive until now. In this review, we analyse the effects of circRNAs on the TME from various perspectives, including immune surveillance, angiogenesis, hypoxia, matrix remodelling, exo-circRNAs and chemoradiation resistance. Currently, the enormous potential for circRNA use in targeted therapy and as noninvasive biomarkers have drawn our attention. We emphasize the prospect of targeting circRNAs as an essential strategy to regulate TME, overcome cancer resistance and improve therapeutic outcomes.
\end{abstract}

Keywords: CircRNAs, Tumour microenvironment, Immunoregulation, Angiogenesis

\section{Introduction}

During the past decades of cancer research, chemo- and radiotherapy have been recognized as the most effective and extensive approaches for cancer treatment, but their clinical applications are limited due to their toxic side effects [1]. The tumour microenvironment (TME) is the product of the crosstalk between different cell types, and plays a crucial role in the progression, metastasis and therapeutic treatment of cancer [2-4]. Therefore, cancer therapeutic strategies have also gradually shifted from malignant tumour cells to the TME and its complex interactions. In recent years, the TME has been considered a prospective breakthrough in molecular diagnosis and treatment, and TME research has provided new ideas for cancer therapy and possible preventive strategies $[5,6]$. Critical issues regarding the roles of the TME in tumour progression and response to treatment include its effects

\footnotetext{
* Correspondence: 1999liujb@163.com; fcclixl2@zzu.edu.cn; zqsun82@csu.edu.cn

${ }^{1}$ Department of Colorectal Surgery, The First Affiliated Hospital of Zhengzhou University, Zhengzhou 450052, China

${ }^{2}$ Department of Geriatric Medicine, The First Affiliated Hospital of Zhengzhou University, Zhengzhou 450052, China

Full list of author information is available at the end of the article
}

on immunology [7], angiogenesis [8], metastasis and hypoxia [9].

Extensive and in-depth research on the TME should importantly involve noncoding RNAs (ncRNAs), such as microRNAs (miRNAs) [10-12] and long ncRNAs (lncRNAs) [13-15]. With the broad application of highthroughput RNA sequencing (RNA-seq), numerous circular RNAs (circRNAs) have been identified and characterized in humans and other eukaryotes. In recent years, circRNAs have also been involved in TME research. CircRNAs are a class of single-stranded closed circle molecules that lack $5^{\prime}$ and $3^{\prime}$ ends and poly (A) tails, which makes them resistant to RNase $\mathrm{R}$ and more stable than linear RNAs [16]. Numerous studies on the distinct properties and diverse cellular functions of circRNAs have revealed their importance in tumourigenesis, reproduction, metastasis, invasion, stem cell regulation and radioresistance, suggesting that circRNAs may potentially serve as required novel biomarkers and therapeutic targets for cancer treatment [17, 18]. Previous studies have focused more on the regulation of tumour parenchyma cells, and recent studies have demonstrated that circRNAs play an essential role in regulating the TME $[19,20]$. 
In this review, we summarize the roles of circRNAs in the TME and lay the foundation for their usability in targeted therapy. In particular, we emphasize the roles of circRNAs in regulating tumour immunity and angiogenesis.

\section{The tumour microenvironment}

Since 1989, and following the description of the "seed and soil theory" hypothesis by Stephen Paget, increasing attention has been paid to the association between cancer and the TME $[21,22]$, and the TME was deemed the key contributor to tumour proliferation, immune evasion, metastasis and chemoresistance [23]. Accumulating evidence has confirmed that tumour cells must recruit and reprogram the surrounding normal cells to contribute to tumour progression [24]. The TME is a complex scaffold of stromal cells, extracellular matrix (ECM) components, and exosomes [25]. The stromal cells include cancer-associated fibroblasts (CAFs), endothelial cells, pericytes, and immune cells, such as various types of lymphocytes, natural killer (NK) cells, regulatory $\mathrm{T}$ cells (Treg), tumour-associated macrophages (TAMs), and myeloid-derived suppressor cells chemokines, matrix metalloproteinases (MMPS), integrins, and other secreted molecules [26]. The dynamic changes in the components described above and other factors related to the TME, such as hypoxia and acidosis, play a significant role in the occurrence, progression and metastasis of tumours (such as triggering an adjustment of the ECM and inducing angiogenesis and immune cell responses in the TME). Different sites and types of tumours have specific TMEs, and the heterogeneity and dynamic changes in the TME lead to cancer therapeutic resistance [27]. Therefore, a thorough understanding of the TME may provide important clues for finding new treatment options and improving the efficacy of treatment.

Over the past few decades, our understanding of TME dynamics has improved exponentially. The TME comprises numerous signaling molecules and pathways that affect angiogenic responses and immune suppression [28]. The approval of antiangiogenic drugs and, more recently, immune checkpoints, by the US Food and Drug Administration (FDA) have reinvigorated the enthusiasm of researchers to understand the role of the TME [29]. Therefore, an in-depth understanding of the molecular mechanisms that regulate tumour angiogenesis and immune suppression may contribute to the development of new therapies that target the dissemination/metastasis of tumour cells.

\section{CircRNAs}

With the rapid development of RNA-seq technologies and bioinformatics, new information regarding circRNAs has gradually been presented. Emerging evidence demonstrates that circRNAs are widespread in eukaryotic cells and have several important properties and numerous biological functions, making circRNAs a focal point of scientific research in the ncRNA field.

CircRNAs have the following special characteristics. (1) Abundance: circRNA expression is widespread in diverse species, such as archaea [30], plants (Arabidopsis thaliana and rice) [31, 32], mice [33], zebrafish [34], Drosophila [35] and humans [36]. In addition to their broad expression ranges, approximately one-eighth of the genes expressed in humans produce detectable circRNAs that are expressed at levels more than 10 times higher than the corresponding linear mRNA levels [37, 38]. (2) Stability: due to their covalently closed loop structure and absence of free terminals that confer resistance to RNase R, circRNAs are much more stable than linear RNAs $[16,39]$. (3) Conservation: circRNAs exhibit high levels of conservation regardless of the evolutionary distance between species. For example, approximately 15,000 circRNAs are expressed in both human and mouse orthologous loci, representing approximately $15 \%$ and $40 \%$ of the total circRNAs in humans and mice, respectively [40]. (4) Specificity: in terms of cell type, tissue or developmental stage, circRNAs often show specific expression [41-44].

Numerous circRNA biological functions have been successively clarified with thorough and extensive research, and some are listed here. (1) CircRNAs are specific miRNA "sponges" or "reservoirs". As competitive endogenous RNAs (ceRNAs), circRNAs contain shared miRNA response elements (MREs) that can interact with target miRNAs. Acting as miRNA sponges, circRNAs can adsorb miRNAs through miRNA binding to the MREs of the circRNAs, thereby preventing miRNAs from complementary pairing with target mRNA 3'-UTR regions; this regulation results in the upregulation of target mRNA expression [45-47]. For example, the most well-known circRNA is CDR1as (antisense to the cerebellar degeneration-related protein 1 transcript, also known as ciRS-7), which contains more than 70 MREs, and it serves as a miR-7 sponge, resulting in reduced miR-7 activity and increased expression of miR-7targeted transcripts [45]. In addition to acting as specific inhibitors of target miRNAs by functioning as miRNA "sponges", circRNAs have the opposite ability to stabilize or activate the functions of miRNAs, leading to their designation as so-called miRNA "reservoirs". For example, ciRS-7 is sensitive to miR-671, and the miR-671dependent Ago2-involved cleavage leads to a disruption of the ciRS-7 and miR-7 association, which ultimately releases miR-7 [48]. Thus, based on the accumulation and storage of miR-7 on ciRS-7, we can consider ciRS-7 to be a miR-7 "reservoir" ready to be activated [48]. Similarly, circHIAT1 protects three of its targets, miR$195-5 p / 29 a-3 p / 29 c-3 p$, from the inhibition mediated by the androgen receptor (AR); circHIAT1 associates with 
miRNA binding sites, thereby functioning as a miRNA "reservoir" to stabilize miRNAs and suppress the downstream CDC42 level [49]. (2) CircRNAs interact with RNA-binding proteins (RBPs). RBPs play a central role in gene transcription and translation. The interaction of circRNAs and RBPs is involved in the composition of circRNA functional basis, including circRNA formation, post-transcriptional regulation, and translation [50-53], and such interactions have a role in the execution of circRNA functions [54-56]. (3) CircRNAs act as protein/ peptide translators. CircRNAs are reported to function as translation templates, and they may encode proteins/ peptides involved in tumour pathogenesis and progress $[57,58]$. (4) CircRNAs act as regulators of gene transcription and expression. In addition to regulating gene expression through their role as miRNA sponges, circRNAs also modulate gene expression at transcriptional and posttranscriptional levels [52, 59, 60].

Most aberrantly expressed circRNAs may serve as important regulators of cancer progression through the modulation of numerous cancer hallmarks, functioning to sustain proliferative signalling, promote tumour and antitumour immunity, induce angiogenesis, promote invasion and metastasis, and deregulate cellular energetics [61]. CircRNAs as well as their various functions in the TME are summarized in Table 1.

\section{CircRNAs mediate tumour immune surveillance}

It is one of the focuses of immunology research to fully understand the molecular mechanism of the cancerrelated immunity that affects cancer development and progression, which may be beneficial for the development of more effective immunotherapeutic strategies. Previous studies have shown that cancer-related immunity plays a dual role in cancer, functioning to both protect the host and promote tumour growth $[62,63]$. For example, cancer-related immune responses can protect the host by destroying cancer cells or inhibiting their outgrowth; on the other hand, they can also promote tumour progression by selecting for tumour escape variants or establishing conditions within the TME that facilitate the development of a tumour-specific adaptive immune response [64]. In recent years, circRNAs have been found to play a potential part in regulating tumour immunity. As immune system antigens, exogenously purified circRNAs may mediate the activation of innate immunity by activating the retinoic acid-inducible gene I (RIG-I)-mediated pathway in vitro [65]. CircRNAinduced nucleic acid sensor RIG-I is a well-known innate immunity regulator [66, 67], and RIG-I agonists have been shown to activate anticancer immune responses to fight tumours [68, 69]. Therefore, exogenous circRNAs entering tumour cells have the potential to affect RIG-I and activate antitumour immunity (Fig. 1b). Studies have shown that tumour cell-derived exosomes are involved in multiple immune activities in tumour progression [58, 70, 71]. In addition, some exosomal RNAs from donor cells, including circRNA, can function in recipient cells [72-74]. These studies indicated that circRNAs may be transported to immunocytes through exosomes and extracellular vesicles (EVs) to regulate immune responses in tumours by functioning as potential tumour antigens (Fig. 1a). For instance, researchers discovered that circRNAs were downregulated and transferred to exosomes from KRAS mutant colon cancer cells [75]. In addition, circRNAs can coprecipitate with EVs, and since EVs can be taken up by other cells, excreted circRNAs may contribute to cell-to-cell communication [76]. Moreover, the plasma expression levels of circRNAs are closely related to the levels of tumourinfiltrating lymphocytes (TILs) in the TME [77]. Therefore, circRNAs have rich potential to regulate tumour immunity.

\section{CircRNAs regulate immune escape via PD-L1}

Tumour immune escape refers to the phenomenon of tumour cells growing and metastasizing via various mechanisms to avoid recognition and attack by the immune system. The mechanism of tumour immune escape includes immunosuppression. Programmed death 1/programmed death-ligand 1 (PD-1/PD-L1), known as an immune checkpoint, is an important component of tumour immunosuppression [78]. One recent study showed that a circRNA acted as a ceRNA to regulate the expression of PD-L1, thereby helping the tumour escape immune surveillance [79]. The interaction between PD-1 and PD-L1 can effectively inhibit the activation of effector $\mathrm{T}$ lymphocytes, ultimately leading to tumour immune escape [80]. The inhibitory checkpoint PD-L1 is highly expressed in multiple malignancies [81, 82], so developing drugs that block the PD-L1 pathway is an attractive potential cancer immunotherapy. Currently, drugs targeting PD-L1 are being tested in clinical trials against multiple cancer types, including colorectal cancer (CRC) [83], nonsmall cell lung cancer (NSCLC) $[84,85]$, and urothelial carcinoma [86]. In the past few decades, the roles of miRNAs in regulating the expression of the PD-1/PD-L1 immune checkpoint and the sensitivity of tumours to chemotherapy drugs have been well studied [87, 88], revealing that circRNAs contribute to immune escape through a circRNA-miRNA-PD-1/PD-L1 axis (Fig. 1c). For instance, the circRNA circ-0020397 was found to bind to miR-138, suppress miR-138 activity, and consequently promote the expression of miR-138 targets, such as telomerase reverse transcriptase and PD-L1, in CRC cells (CRCCs). Due to the high circ-0020397 expression in CRCCs, PD-L1 is upregulated and can interact with PD-1 to induce $\mathrm{T}$ cell apoptosis and inhibit $\mathrm{T}$ cell activation and 
Table 1 Summary of circRNAs and their functions in the TME

\begin{tabular}{|c|c|c|c|c|c|c|}
\hline Roles & CircRNAs & Origin & Expression & Functions & Targets & References \\
\hline \multirow{5}{*}{$\begin{array}{l}\text { mediating } \\
\text { tumour immune } \\
\text { surveillance }\end{array}$} & circRNAs & exogenous & - & $\begin{array}{l}\text { probably activated antitumour } \\
\text { immunity }\end{array}$ & R/G-I/ immunocytes & [65] \\
\hline & circRNAs & exosomes & - & $\begin{array}{l}\text { probably regulated antitumour } \\
\text { immunity }\end{array}$ & immunocytes & $\begin{array}{l}{[58,70,72,} \\
73]\end{array}$ \\
\hline & circ-0020397 & CRC & up & $\begin{array}{l}\text { inhibited the activation and } \\
\text { proliferation of T cells, and } \\
\text { promoted the viability and } \\
\text { invasion of CRC cells }\end{array}$ & miR-138/ PD-L1 & [79] \\
\hline & circARSP91 & $\mathrm{HCC}$ & up & $\begin{array}{l}\text { enhanced the cytotoxicity } \\
\text { of NK cell and upregulated } \\
\text { NK-mediated immune } \\
\text { responses }\end{array}$ & ULBP1 & [92] \\
\hline & circ-0000977 & PC & - & $\begin{array}{l}\text { inhibited the killing ability } \\
\text { of NK }\end{array}$ & miR-153 /HIF1a, ADAM10 & [168] \\
\hline \multirow[t]{8}{*}{$\begin{array}{l}\text { promoting } \\
\text { angiogenesis }\end{array}$} & circ0001429 & $\begin{array}{l}\text { bladder } \\
\text { cancer }\end{array}$ & up & $\begin{array}{l}\text { promoted cell metastasis } \\
\text { and angiogenesis }\end{array}$ & miR-205-5p NEGFA & [99] \\
\hline & circSCAF11 & glioma & up & $\begin{array}{l}\text { stimulated angiogenesis } \\
\text { and tumourigenesis }\end{array}$ & miR-421/SP1/ VEGFA & [100] \\
\hline & $\begin{array}{l}\text { circRNA } \\
\text { cZNF292 }\end{array}$ & glioma & up & $\begin{array}{l}\text { promoted cell proliferation } \\
\text { and angiogenesis }\end{array}$ & $\begin{array}{l}\text { VEGFR-1/2, p-VEGFR-1/2 } \\
\text { and EGFR }\end{array}$ & [101] \\
\hline & $\begin{array}{l}\text { circRNA } \\
\text { cZNF292 }\end{array}$ & hepatoma & up & $\begin{array}{l}\text { promoting cell proliferation, } \\
\text { VM, and radioresistance }\end{array}$ & sox9, Wnt/B-catenin & [103] \\
\hline & circ-SHKBP1I & GECs & up & stimulated angiogenesis & $\begin{array}{l}\text { miR-544a/ FOXP1/ AGGF1 } \\
\text { or miR-379/ FOXP2/ AGGF1 }\end{array}$ & {$[20]$} \\
\hline & circ-0010729 & HUVECS & up & $\begin{array}{l}\text { promoted vascular } \\
\text { endothelial cell proliferation }\end{array}$ & miR-186 /HIF1a & [104] \\
\hline & circ-002136 & GECs & up & stimulated angiogenesis & $\begin{array}{l}\text { FUS/circ-002136/miR-138-5p } \\
\text { /SOX13 feedback loop }\end{array}$ & {$[105]$} \\
\hline & circ-DICER1 & GECs & up & promoted angiogenesis & $\begin{array}{l}\text { MOV10/circ-DICER1 } \\
\text { /miR-103a-3p (miR-382-5p) } \\
\text { /ZIC4 Hsp90ß/PI3KAkt }\end{array}$ & [106] \\
\hline \multirow[t]{3}{*}{ inhibiting angiogenesis } & circHIPK3 & $\begin{array}{l}\text { bladder } \\
\text { cancer }\end{array}$ & down & $\begin{array}{l}\text { inhibited cell migration, } \\
\text { invasion, and angiogenesis }\end{array}$ & $\begin{array}{l}\text { miR-558/ HPSE/ MMP-9 } \\
\text { and VEGF }\end{array}$ & [107] \\
\hline & circSMARCA5 & GBM & down & inhibited angiogenesis & VEGFA, SRSF1 & \\
\hline & circ-0003575 & HUVECS & up & inhibiting angiogenesis & $\begin{array}{l}\text { potential circRNA-miRNA- } \\
\text { mRNA network }\end{array}$ & [110] \\
\hline $\begin{array}{l}\text { improving } \\
\text { endothelial cell } \\
\text { permeability }\end{array}$ & circRNA IARS & $\begin{array}{l}\text { exosomes } \\
\text { derived from } \\
\text { PC cells }\end{array}$ & up & $\begin{array}{l}\text { enhanced cell invasion, } \\
\text { metastasis and endothelial } \\
\text { cell permeability }\end{array}$ & miR-122/ RhoA/ F-actin & [112] \\
\hline \multirow[t]{6}{*}{ hypoxia } & circDENND4C & breast cancer & up & promoted cell proliferation & - & \\
\hline & circDENND4C & breast cancer & up & $\begin{array}{l}\text { promoted cell glycolysis, } \\
\text { migration, invasion and } \\
\text { proliferation }\end{array}$ & miR-200b and miR-200c & [116] \\
\hline & circDENND2A & glioma & up & $\begin{array}{l}\text { promoted cell migration } \\
\text { and invasion }\end{array}$ & miR-625-5p & [169] \\
\hline & circ-0000977 & $P C$ & - & mediated immune escape & miR-153/ HIF1a & [168] \\
\hline & circ-0010729 & HUVECS & up & $\begin{array}{l}\text { enhanced cell proliferation, } \\
\text { migration and suppressed } \\
\text { apoptosis }\end{array}$ & miR-186/ HIF1a & [104] \\
\hline & $\begin{array}{l}\text { circRNA } \\
\text { cZNF292 }\end{array}$ & hepatoma & up & $\begin{array}{l}\text { promoted cell proliferation, } \\
\text { VM, and radioresistance }\end{array}$ & SOX9, Wnt/ß-catenin & [103] \\
\hline \multirow[t]{2}{*}{$\begin{array}{l}\text { causing ECM } \\
\text { remodelling }\end{array}$} & circ-0000096 & gastric cancer & down & $\begin{array}{l}\text { affected cell growth and } \\
\text { migration }\end{array}$ & VEGF, MMP-2 and MMP-9 & [120] \\
\hline & circLMNB1 & CRC & up & $\begin{array}{l}\text { promoted cell dissemination, } \\
\text { invasion and EMT }\end{array}$ & MMP-2 and MMP-9 & [121] \\
\hline
\end{tabular}


Table 1 Summary of circRNAs and their functions in the TME (Continued)

\begin{tabular}{|c|c|c|c|c|c|c|}
\hline Roles & CircRNAs & Origin & Expression & Functions & Targets & References \\
\hline & circDENND4C & breast cancer & up & $\begin{array}{l}\text { suppressed cell migration } \\
\text { and invasion }\end{array}$ & MMP-2 and MMP-9 & [116] \\
\hline & circ-0007334 & PDAC & up & promoted cell invasion & $\begin{array}{l}\text { miR-144-3p and miR-577/ } \\
\text { COL1A1, MMP-7 }\end{array}$ & [122] \\
\hline & $\begin{array}{l}\text { circRNA } \\
\text { cSMARCA5 }\end{array}$ & $\mathrm{HCC}$ & down & $\begin{array}{l}\text { inhibited cell proliferation } \\
\text { and migration }\end{array}$ & $\begin{array}{l}\text { miRNA-17-3p and } \\
\text { miRNA-181b-5p/ TIMP-3 }\end{array}$ & [124] \\
\hline \multirow[t]{3}{*}{ exosomes } & circRNA IARS & $\begin{array}{l}\text { exosomes derived } \\
\text { from PC cells }\end{array}$ & up & $\begin{array}{l}\text { promotedcell invasion } \\
\text { and metastasis }\end{array}$ & miR-122 & [112] \\
\hline & circ-DB & $\begin{array}{l}\text { exosomes derived } \\
\text { from adipocytes }\end{array}$ & up & $\begin{array}{l}\text { promoted tumourigenesis } \\
\text { and metastasis of HCC }\end{array}$ & miR-34a/ USP7/ cyclin A2 & [135] \\
\hline & $\begin{array}{l}\text { ciRS-133 } \\
\text { (circ-0010522) }\end{array}$ & $\begin{array}{l}\text { exosomes derived } \\
\text { from GC cells }\end{array}$ & up & $\begin{array}{l}\text { promoted white adipose } \\
\text { browning in patients with } \\
\text { gastric cancer }\end{array}$ & miR-133/ PRDM16 & [119] \\
\hline
\end{tabular}

proliferation, leading to cancer immune escape. Studies have shown better clinical efficacy of PD-1/PD-L1 blockers in patients with high PD-L1 expression [79]. Therefore, regulating PD-1/PD-L1 expression by targeting related circRNAs may be a direction of future immune checkpoint therapeutic research.

\section{CircRNAs regulate the cytotoxicity of natural killer cells}

Natural killer (NK) cells are considered the first line of defence for host immune surveillance and play a vital role in antitumour immunotherapy. Because NK cells have no major histocompatibility complex (MHC) limitations on the recognition and destruction of target cells, an

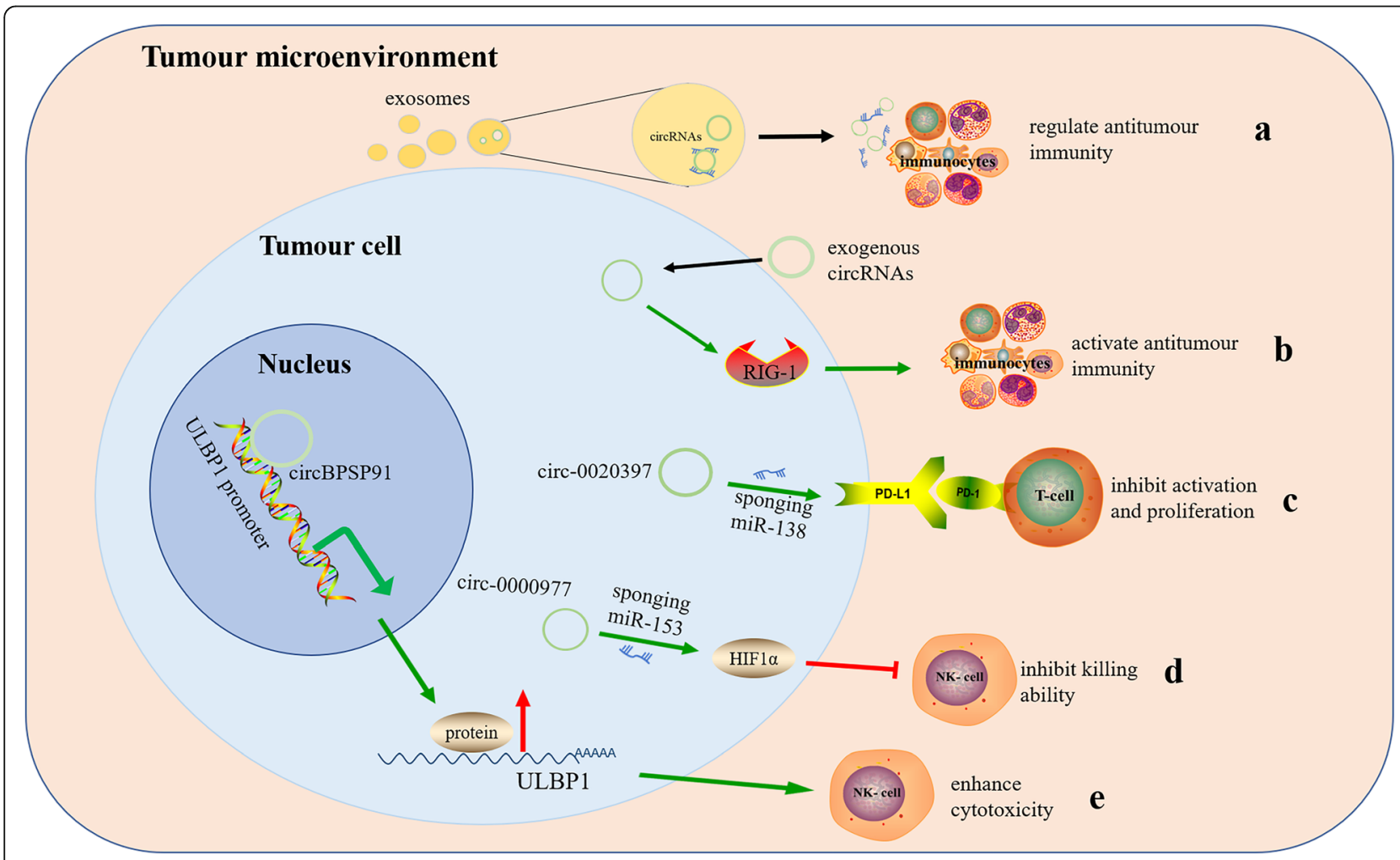

Fig. 1 CircRNAs play a vital role in regulating tumour immunity. a circRNAs are transported to immunocytes through exosomes and extracellular vesicles secreted by the tumour cell to regulate immune responses. $\mathbf{b}$ exogenous circRNAs entering tumor cells may activate R/G-1-mediated pathway and activate antitumour immunity. c circRNAs promote the expression of PD-L1 in tumour cells, inhibit the activation and proliferation of T cells, and induce T cell apoptosis. $\mathbf{d}$ circRNAs can inhibit the killing ability of NK cells through the circ-0000977/miR-153/HIF1a axis. e circRNAs can also upregulate target mRNAs and ULBP1 protein levels to enhance the cytotoxicity of NK cell and upregulate NK-mediated immune responses. The green arrow indicates stimulatory modification, and the red "T" symbol indicates inhibitory modification 
increasing number of immunostimulants can be produced to enhance cell killing [89]. Increasing experimental evidence has shown that the activity and density of NK cells in the TME correlates with prognoses in a variety of cancers [90]. Xu reported that the densities of infiltrating NK cells in tumour nests and stroma were significantly associated with patients' postoperative prognoses [91]. Recent studies elucidated another mechanism by which tumour cell-derived circRNAs participate in tumour immune surveillance by enhancing NK cell activity and upregulating NK-mediated immune responses. For instance, in hepatocellular carcinoma (HCC) cells, circARSP91 was reported to enhance the cytotoxicity of NK cells by upregulating the expression of UL16 binding protein 1 (ULBP1) at the mRNA and protein levels (Fig. 1e). In addition to acting as miRNA sponges, circRNAs also regulate the translation of target mRNAs at the posttranscriptional levels. For example, circARSP91 may interact with the ULBP1 promoter region and recruit RNA polymerase II to enhance the expression of the ULBP1 gene (Fig. 1e). In this study, ULBP1 was upregulated by circARSP91 and assisted NK cells in identifying and attacking target tumour cells [92]. In addition, a recent study showed that hypoxia induced the expression of circ-0000977 in pancreatic cancer (PC). Circ-0000977 knockdown enhanced the killing effect of NK cells on PC cells under hypoxic conditions through hypoxia-inducible factor 1alpha (HIF1 $\alpha)$. The circ-0000977/miR-153/HIF1 $\alpha$ axis modulates the HIF1 $\alpha$-mediated immune escape of PC cells by downregulating the sensitivity to NK cellmediated lysis [93] (Fig. 1d). Thus, the above studies indicate that circRNAs can modulate the activity or cytotoxicity of immune cells in the TME, thereby mediating tumour immune surveillance.

\section{CircRNAs regulate angiogenesis and endothelial monolayer permeability}

Angiogenesis is a complex process by which new blood vessels are formed from pre-existing vessels by sprouting, remodelling and expanding primary vascular networks [94]. Inducing angiogenesis by influencing the microenvironment is one hallmark of cancer. The growth and metastasis of solid tumours depend on angiogenesis to supply sufficient nutrients and oxygen to cancer cells. The tumour-associated neovasculature plays key roles in multiple aspects of tumour biology, including tumour dissemination/metastasis, metabolic deregulation and cancer stem cell (CSC) maintenance, and current research suggests that circRNAs mediate angiogenesis [20]. In the TME, circRNAs play an essential role in proangiogenic and antiangiogenic signalling networks related to the "angiogenic switch".

\section{Heterogeneity of angiogenesis regulated by circRNAs}

The majority of human tumours present startling heterogeneity in many of their morphological and physiological features, such as their expression of cell surface receptors and proliferative and angiogenic potential [95]. In recent years, circRNAs have been shown to act as auxiliary diagnostic biomarkers of diverse cancers, and their expression is reported to be heterogeneous in different cancers [96]. Similarly, the latest research suggests that circRNAs are heterogeneous in their regulation of tumour angiogenesis.

\section{Promoting angiogenesis}

On the one hand, circRNAs directly regulate the expression of vascular endothelial growth factor A (VEGFA) (Fig. 2a). For instance, circRNA-MYLK and VEGFA were significantly upregulated and co-expressed in breast cancer. Importantly, overexpressing circRNA-MYLK promoted the tubular structure formation of human umbilical vein endothelial cells (HUVECs) in vitro and angiogenesis in vivo by upregulating VEGFA [97]. As a member of the growth factor family, VEGFA has a large capacity to stimulate the angiogenic milieu, as it can increases microvascular density and vascular permeability, which promotes tumour angiogenesis and metastasis and leads to the resistance of tumours to antiangiogenic therapy [98]. Similarly, circ0001429 was found to upregulate VEGFA expression by sponging miR-205-5p to promote the growth and metastasis of bladder cancer cells [99]. CircSCAF11 activates the VEGFA transcription via the miR-421/SP1/VEGFA axis, which stimulates angiogenesis and tumourigenesis of glioma [100]. Furthermore, the circRNA cZNF292, generally expressed in a hypoxic environment, was also discovered to be expressed in glioma U87MG and U251 cells [101]. This study showed that silencing circRNA cZNF292 could significantly inhibit the proliferation and angiogenic potential of glioma cells by downregulating the expression of VEGFR-1/2, p-VEGFR-1/2 and EGFR. CircRNAs were demonstrated to be abundantly expressed in endothelial cells, and the circRNAs cZNF292, cAFF1, and $\mathrm{CDENND} 4 \mathrm{C}$ were upregulated by hypoxia. Among them, cZNF292, a significantly hypoxia-regulated circRNA, exhibits a proangiogenic function in endothelial cells [102]. Interestingly, while further exploring the mechanism of the angiogenic function of cZNF292, researchers found that cZNF292 had neither a cisregulatory function in host gene expression nor a putative function as a miRNA sponge [102]. Further investigation showed that cZNF292 knockdown inhibited hepatoma vasculogenic mimicry (VM) and radioresistance in vitro and in vivo by increasing sex-determining region Y (SRY)-box 9 (SOX9) nuclear translocation, subsequently reducing $\mathrm{Wnt} / \beta$-catenin signalling pathway activity [103]. 


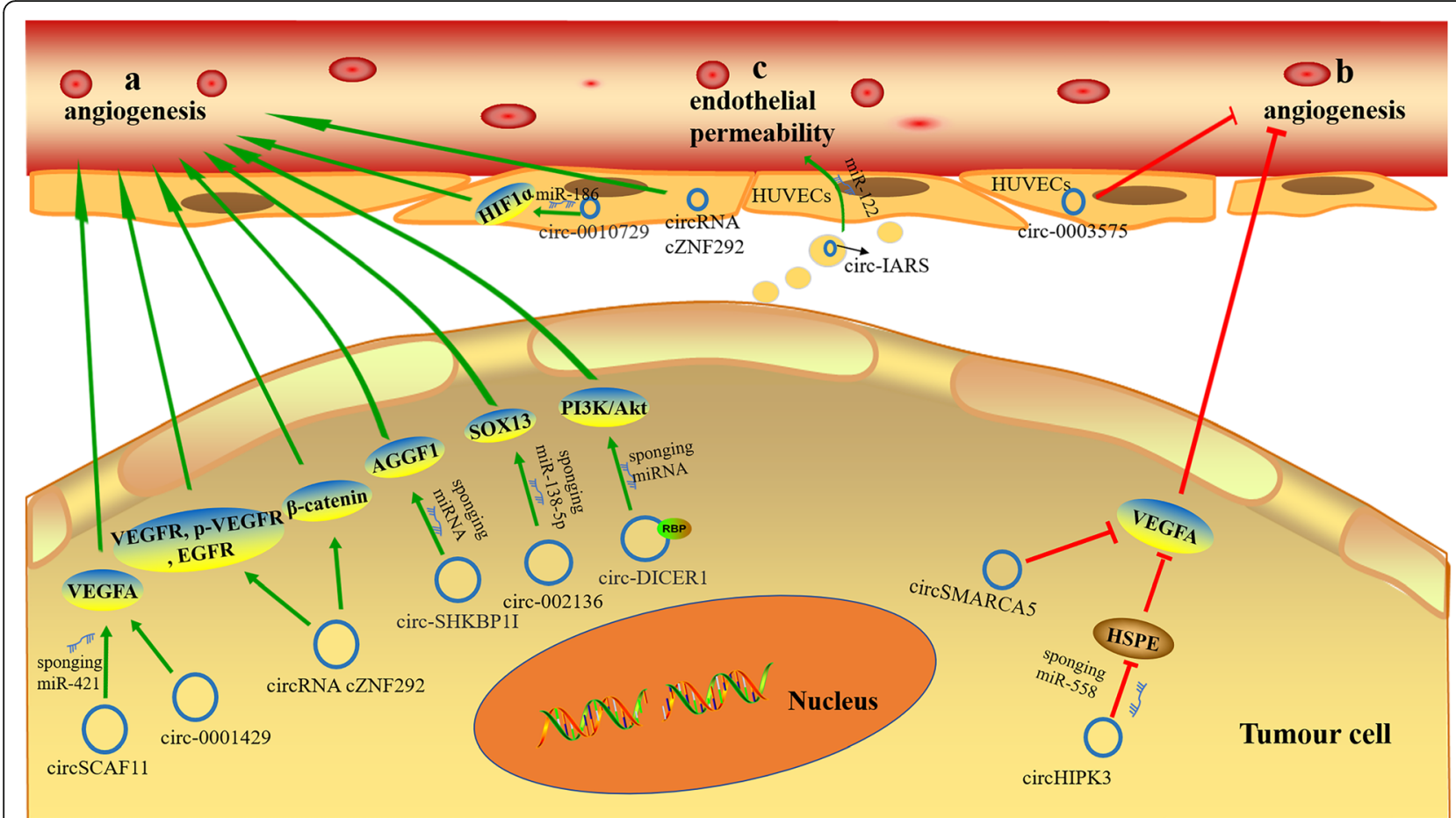

Fig. 2 The functional roles of circRNAs in tumour angiogenesis and endothelial monolayer permeability. a circRNAs promote angiogenesis. $\mathbf{b}$ circRNAs inhibit angiogenesis. c circRNAs promote endothelial monolayer permeability. The green arrow indicates stimulatory modification, and the red "T" symbol indicates inhibitory modification

On the other hand, circRNAs regulate the expression of downstream molecules related to angiogenesis by acting as specific miRNA "sponges" (Fig. 2a). For instance, circSHKBP1I was shown to increase the expression of AGGF1 via the miR-544a/FOXP1 or miR-379/FOXP2 pathway, which stimulated glioma angiogenesis [20]. The researchers also utilized loss-of-function experiments in HUVECs to demonstrate that circ-0010729 knockdown suppressed proliferation and migration and enhanced apoptosis. The authors also identified that the crucial regulatory effect of circ-0010729 on vascular endothelial cells was mediated by targeting the miR-186/HIF1 $\alpha$ axis [104]. Emerging research indicates that the FUS/circ002136/miR-138-5p/SOX13 feedback loop plays a critical role in promoting glioma angiogenesis. This study found that circ-002136 was highly expressed in gliomaassociated endothelial cells (GECs), and silencing circ002136 inhibited glioma angiogenesis [105].

Additionally, circRNAs also simultaneously act as RBPs and miRNA "sponges" (Fig. 2a). For instance, by binding the RBP MOV10 and acting as a molecular sponge to adsorb miR-103a-3p/miR-382-5p, circDICER1 upregulated the expression of ZIC4 and its downstream target Hsp90 $\beta$. Upregulated circ-DICER1 in GECs promoted angiogenesis by activating the MOV10/ circ-DICER1/miR-103a-3p (miR-382-5p)/ZIC4 Hsp90ß/ PI3K/Akt signalling pathway [106]. Therefore, circRNAs promote angiogenesis through different mechanisms to create a favourable microenvironment for tumour growth and metastasis.

\section{Inhibiting angiogenesis}

In contrast to the above proangiogenic functions, circRNAs also play an essential antiangiogenic role (Fig. 2b). CircHIPK3 was reportedly downregulated in human bladder cancer. Enforced overexpression of circHIPK3 significantly inhibited the migration, invasion, and angiogenesis of bladder cancer cells via sponging miR558 to suppress the expression of heparanase (HPSE) and its downstream targets MMP-9 and VEGF [107]. Moreover, Davide and colleagues found that circSMARCA5 is an upstream regulator of the pro- to antiangiogenic VEGFA isoform ratio within glioblastoma multiform (GBM) cells and acts as a prospective antiangiogenic molecule. CircSMARCA5 acts as sponge for serine- and arginine-rich splicing factor (SRSF1) to regulate angiogenesis via a physical interaction. Additionally, circSMARCA 5 inhibits angiogenesis by inducing VEGFA alternative splicing and decreasing microvascular vessel density [108]. Bevacizumab, a humanized monoclonal antibody against VEGFA, has not produced the expected results in antiangiogenic therapies [109]. CircRNAs as therapeutic targets might be an effective alternative to therapy based on monoclonal 
anti-VEGFA antibodies. Through loss-of-function experiments, researchers also revealed that silencing circ0003575 promoted the proliferation and angiogenesis of HUVECs [110].

The above results led to the determination that different circRNAs play multifaceted and even opposite roles in regulating angiogenesis through multiple mechanisms, thus proving the heterogeneity of circRNAs. Therefore, we speculate that in future studies on angiogenesis inhibitors, how circRNAs play an effective targeted therapeutic role to inhibit angiogenesis will be the research focus.

\section{Endothelial monolayer permeability regulated by circRNAs}

In addition to the regulation of angiogenesis, exosomederived circRNAs can also promote the metastasis and dissemination of cancer cells by regulating the permeability of endothelial cells (Fig. 2c). Tumour metastasis is the main cause of cancer-related death. Tumour endothelial cells, which acquire their specific characteristics in the TME, stimulate the metastasis of tumour cells. In particular, endothelial cells play a crucial role in the initial stage of tumour metastasis [111]. Here, a molecular mechanism by which exosome-derived circRNAs regulate the permeability of endothelial cells in the TME is described. For instance, the circRNA IARS was found to enter HUVECs via exosomes derived from PC cells and enhance endothelial cell permeability by disrupting the tight junction between the endothelium. The above function was achieved through the circRNA IARS/miR122/RhoA/F-actin molecular pathway. Due to the high level of circ-IARS expression in PC tissues and plasma exosomes of patients with metastatic disease, endothelial monolayer permeability was enhanced, which promoted the formation of a microenvironment suitable for tumour invasion and metastasis [112]. Therefore, circRNAs can be potential targets for endothelial cells in the initial stage of tumour metastasis, helping to prevent early tumour cell metastasis by inhibiting endothelial cell permeability.

\section{Hypoxia regulates circRNA production}

Hypoxia is a key feature of the TME and has a profound impact on cancer aggressiveness and therapy. The molecular mechanisms of responses to hypoxia are extremely complex. HIFs, transcriptional regulators, play a key role in regulating the responses of the TME and the proliferation and metastasis of cancer cells by activating the transcription of downstream oncogenes containing hypoxia-responsive elements (HREs) and regulating various signal pathways $[113,114]$. For instance, circRNAs regulated by hypoxia in endothelial cells were identified for the first time [102]. Subsequently, in breast cancer cells, HIF $1 \alpha$ was reported to be crucial for upregulating circDENND4C under hypoxic conditions, indicating that circDENND4C is an HIF1 $\alpha$-associated circRNA and promotes the proliferation of breast cancer cells [115] . Under hypoxia, loss-of-function experiments indicate that circDENND4C knockdown could suppress glycolysis, migration and invasion by increasing miR-200b and miR-200c in breast cancer cells [116]. Another study also showed that hypoxia induced the expression of circDENND2A, which promoted the migration and invasion of glioma cells by sponging miR-625-5p. Via clinical analysis, this study also demonstrated the existence of a circDENND2A/miR-625-5p axis in glioma tissues, which was associated with HIF1 $\alpha$ [19]. The hypoxia-induced expression of circ-0000977 and the circ-0000977/miR153 axis modulates the HIF1 $\alpha$-mediated immune escape of PC cells via the miR-153 downstream target HIF1 $\alpha$ [93]. Hypoxia also induced upregulation of circ-0010729, which was shown to regulate vascular endothelial cell proliferation and apoptosis via targeting the miR-186/HIF1 $\alpha$ axis [104]. Interestingly, another study indicated that cZNF292 was induced by hypoxia in a time-dependent manner in hepatoma cells independent of HIF $1 \alpha$, promoting hypoxic hepatoma proliferation, VM, and radioresistance [103]. As hypoxic microenvironment-related circRNAs participate in angiogenesis, metastasis, invasion, and resistance to radiation therapy (Fig. 3), circRNAs have great potential to be used as targets and may play crucial roles in blocking many undesirable traits for cancer under hypoxia.

\section{Remodelling of the extracellular matrix (ECM)}

The TME is mainly composed of stromal cells and ECM components. The ECM is a highly dynamic structural network composed of many matrix components that continuously undergo remodelling mediated by several matrix-degrading enzymes in the process of tumourigenesis and development [117].

The ECM is degraded by various proteases, with the MMP family having a pivotal role. These enzymes (MMPs) support tumour cell invasion of the basement membrane and stroma, blood vessel penetration, and metastasis by interacting with macromolecules on the basement membrane to degrade and stimulate ECM remodelling [118]. CircRNAs are reported to be involved in ECM remodelling by regulating the expression of MMPs $[116,119]$. For example, in gastric cancer cells, the protein expression levels of VEGF and the migrationrelated proteins MMP-2 and MMP-9 were significantly decreased after knockdown of circ-0000096, indicating that circ-0000096 may affect cell growth and migration by regulating matrix remodelling and angiogenesis [120]. CircLMNB1, which is highly expressed in CRC, downregulates MMP-2 and MMP-9 expression and inhibits 


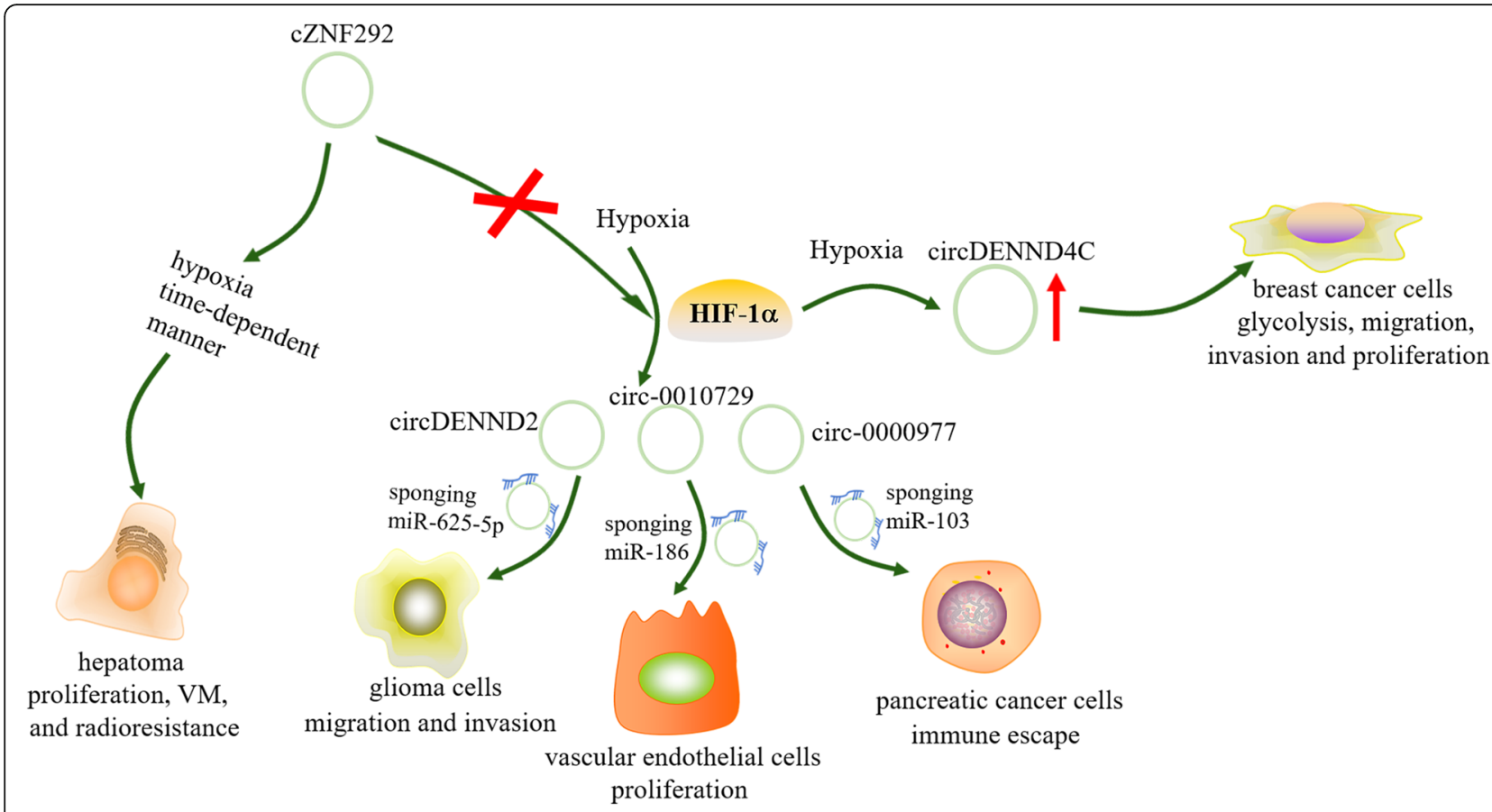

Fig. 3 Hypoxia-related circRNAs promote the proliferation, migration and invasion of cancer cells and are also associated with angiogenesis and anti-radiation therapy of cancer. The green arrow indicates stimulatory modification

epithelial-mesenchymal transition (EMT) after gene knockdown, thereby affecting tumour dissemination and invasion [121]. Under hypoxic conditions, silencing circDENND4C significantly reduced the migration and invasion of breast cancer cells by downregulating the protein expression levels of MMP-2 and MMP-9 [116]. Remodelling of the ECM and angiogenesis in cancer stroma can be considered part of the tumour invasion processes. Circ0007334 regulates MMP-7 and collagen type I alpha 1 chain (COL1A1) by competitively adsorbing miR-144-3p and miR-577 to enhance the expression and functions of MMP-7 and COL1A1 in pancreatic ductal adenocarcinoma (PDAC) [122]. COL1A1 is responsible for encoding ECM remodelling-related collagens, which are the most abundant proteins in the ECM. COL1A1 is an individual ECM gene and has been reportedly associated with tumour invasion and metastasis [20].

The activity of these MMPs is tightly regulated in numerous ways, such as by transcriptional regulation, proteolytic activation and interaction with tissue inhibitors of metalloproteinases (TIMPs) [123]. TIMPs are endogenous inhibitors that can inhibit the activity of MMPs to prevent degradation of the ECM, and the local balance between TIMPs and MMPs plays a crucial role in ECM homeostasis. Low expression of circRNA cSMARCA5 in HCC can promote the expression of TIMP-3 by sponging miRNA17-3p and miRNA-181b-5p and inhibit the proliferation and migration of HCC cells [124]. Therefore, circRNAs play an important role in the metastasis and invasion of cancer by regulating the TME, especially functioning in matrix remodelling. CircRNAs may serve as key targets for tumour detection and treatment and open new directions for future research.

\section{Exosome-derived circRNAs and the TME}

Exosomes are extracellular vesicles $40-200 \mathrm{~nm}$ in diameter with a lipid bilayer membrane structure; they are secreted by almost all cell types under both physiological and pathological conditions and are widely found in the microenvironment $[125,126]$. Exosomes contain diverse proteins, lipids, DNAs, and RNAs (mRNA, miRNAs, lncRNAs, and circRNAs) [127, 128], which are involved in intercellular communication when they are released and transferred into recipient cells [73, 129, 130]. Intercellular information transmission in the TME is crucial for tumour progression. Numerous studies have shown that abundant and stable circRNAs are present within exosomes [75, 76, 131]. Recently, researchers have revealed that tumour exo-circRNAs may be transported to immunocytes as tumour antigens to activate antitumour immunity or bind to miRNAs and proteins to regulate immunocyte activity. In addition, when exo-circRNAs are transported from tumour cells to immunocytes, they help release the miRNAs into the immunocytes to silence related target genes [132]. Similarly, Bai described two possible main regulatory mechanisms of exocircRNAs by sponging miRNAs [133]. For example, exosomes derived from PC cells carry circRNA IARS to the 
target site (HUVECs). Then, the circRNA is absorbed and bound to miR-122, thereby relieving the inhibition of target gene expression [112]. The TME includes adipocytes $[3,134]$, and one study showed that the exocirc-deubiquitination (exo-circ-DB) derived from adipocytes upregulated the expression levels of USP7 and Cyclin A2 by sponging miR-34a and activating the USP7/CyclinA2 signalling pathway, thereby promoting the tumorigenesis and metastasis of HCC [135]. In addition, plasma exosome-derived ciRS-133 (circ-0010522) aggravates tumour cachexia and increases oxygen consumption by promoting white adipose browning in patients with gastric cancer [119]. Numerous experiments have demonstrated that tumour-related exosomes (TEXs) play an essential role in TME maturation and cancer progression [136-138]. Because circRNAs are located in exosomes, exo-circRNAs are characterized by a transferable targeting ability as well as by the original biological functions of circRNAs. Therefore, the function and potential application of exo-circRNAs in the TME are worthy of affirmation and may be gradually uncovered by future research.

\section{The clinical potential of circRNAs CircRNAs regulate cancer chemoradiation resistance}

Although chemotherapy and radiotherapy are still the preferred methods for cancer therapy behind surgery, local recurrence and distant metastasis still occur in a considerable fraction of cancer patients due to the development of resistance. Intrinsic and extrinsic factors can affect cancer cell resistance to chemoradiation. The extrinsic factors in the TME that promote chemoradiation resistance and tumour recurrence include hypoxia, the ECM, and the expression of angiogenic markers such as VEGF and HIF-1 $\alpha$ [139-142], which may involve circRNAs. Therefore, understanding the regulatory mechanisms of circRNAs involved in radiotherapy and chemotherapy resistance can identify novel targets to optimize therapy.

Recently, studies found that the expression profile of circRNAs was altered in AZD9291-resistant NSCLC cell lines, 5-FU-based chemoradiation-resistant CRC cells, gemcitabine-resistant PC cells, tamoxifen-resistant breast cancer cells and radioresistant oesophageal cancer cells [143-147]. Further analysis revealed that some circRNAs affect the chemoradiation resistance of cancer cells by regulating specific genes or pathways. For example, circ-0043632 regulates the proliferation, migration, and invasion of NSCLC, and AZD9291-resistant NSCLC may bypass the circ-0043632/miR-492/TIMP2 axis [143]. TIMP2 is critical for the regulation of ECM remodelling. In addition, the hypoxic microenvironment makes cancer cells more resistant to radiotherapy [148]. Hypoxia-induced cZNF292 can enhance the radioresistance of hypoxic hepatoma cells [103]. Notably, the presence of CSCs and angiogenesis are closely associated with therapeutic resistance [149-151]. CircRNAs can promote malignant progression and therapeutic resistance via modulating the CSC phenotype $[116,152]$. Because of the close association of circRNAs with angiogenesis, targeting these related circRNAs may provide new insights into the reversal of cancer resistance through the regulation of angiogenesis.

With the increasing involvement of circRNAs elucidated by the study of chemoradiation resistance in cancer cells, as novel biomarkers, circRNAs have great potential for predicting the efficiency of chemoradiation and prognosis or for interfering with chemoradiation resistance as targets in clinical cancer therapy.

\section{CircRNAs as biomarkers in cancer}

The application of biomarkers plays a vital role at all stages of cancer and has become one of the main approaches for cancer diagnosis, determination of prognosis and monitoring of progression. A competent biomarker should have good sensitivity, specificity, repeatability, stability and clinical utility [153]. The expression patterns and characteristics of circRNAs (universality, conservation, tissue/cell specificity, and stability) make them ideal candidates as biomarkers. In addition, circRNAs are enriched in human bodily fluids, such as saliva [154] and blood [155], making them easy to detect and making them suitable biomarkers for the detection of cancers, especially liquid biopsies.

As a diagnostic marker, plasma circ-0001785 had better diagnostic accuracy than CEA and CA15-3 in breast cancer patients, and its plasma level was closely related to the histological grade, the TNM stage and distant metastasis [156]. In addition, circ-0000181, which is downregulated in gastric cancer (GC), was shown to have high tissue specificity and plasma sensitivity, and the expression levels was significantly correlated with tumour diameter, distal metastasis and CA19-9, thus, circ0000181 is a potential noninvasive diagnostic biomarker [157]. Analogously, circ-0000190 was also thought to be a potential diagnostic biomarker for GC, and its sensitivity and specificity are better than traditional markers CEA and CA19-9 [158]. Numerous studies have shown that circRNAs can be potential biomarkers for the early detection and screening of cancer.

As a metastatic marker, the expression of circ-0023988, circ-0008157 and circ-0030388 was elevated in highmetastatic melanoma compared with low-metastatic melanoma [159]. CircRNA-0001178 and circRNA-0000826 have been shown to be significantly differentially expressed between tissue samples from CRC patients with and without liver metastasis, so they may serve as a potential biomarker for liver metastases from CRC [160]. NSCLC tumour specimens exhibited higher circP4HB levels than paired healthy lung samples and were 
associated with metastatic disease [161]. HCC patients with high circ-ZNF652 expression were more prone to vascular invasion, intrahepatic metastasis, and distant metastasis [162].

As a prognostic marker, an elevated level of circHIPK3 was linked to poor prognosis in patients with glioma [163]. CircEPSTI1 and circKIF4A, which are significantly upregulated in triple-negative breast cancer (TNBC), were shown to be closely correlated with poor prognosis $[164,165]$. CiRS-7 was found to be upregulated in CRC tissues was suggested to be an independent prognostic biomarker for the overall survival of patients with CRC [166]. Another study showed that osteosarcoma patients with high expression of circ-NT5C2 had a shorter overall survival (OS) and disease-free survival (DFS) than those with low expression of circ-NT5C2, which implies that circHIPK3 might be a new marker of prognosis in osteosarcoma [167].

In recent years, increasing evidence suggests that circRNAs can be not only clinical biomarkers for the early detection, diagnosis, metastasis and prognosis of cancer but potential therapeutic targets to increase anti-tumour response by regulating the TME. For example, we could target circRNAs to inhibit the expression of PD-L1, activate immune cells, prevent angiogenesis, decrease endothelial cell permeability, block the hypoxia pathway, destroy the ECM, and reverse cancer chemoradiation resistance. Research on these topics will provide new insights into targeted cancer therapy in the future.

\section{Conclusions}

CircRNAs play multiple roles in the TME and can promote or inhibit the immune system and angiogenesis, improve the permeability of endothelial cells to promote cancer metastasis and cause ECM remodelling, which together supports tumour progression (Fig. 4).

Although there is growing evidence regarding the important roles of circRNAs in the TME, research on this topic is still in its infancy, and the physiological and pathological roles of circRNAs in the TME remain to be further explored. There are some problems that urgently need to be solved. First, unlike miRNAs, the study of circRNAs derived from stromal cells (such as CAFs, endothelial cells, pericytes and immune cells) in the TME is still in its infancy, especially regarding circRNAs derived from CAFs. Therefore, much research is needed to expand this field. Additionally, many studies have confirmed that exosomes play an essential role in premetastatic niches, and whether circRNAs are also involved in the formation of pre-metastatic niches needs to be determined. Last but not least, because of the heterogeneity of circRNAs in regulating the TME, the efficacy and safety of targeted therapies need to be tested.

In brief, we drew conclusions about the functions of circRNAs in the TME and further explored the

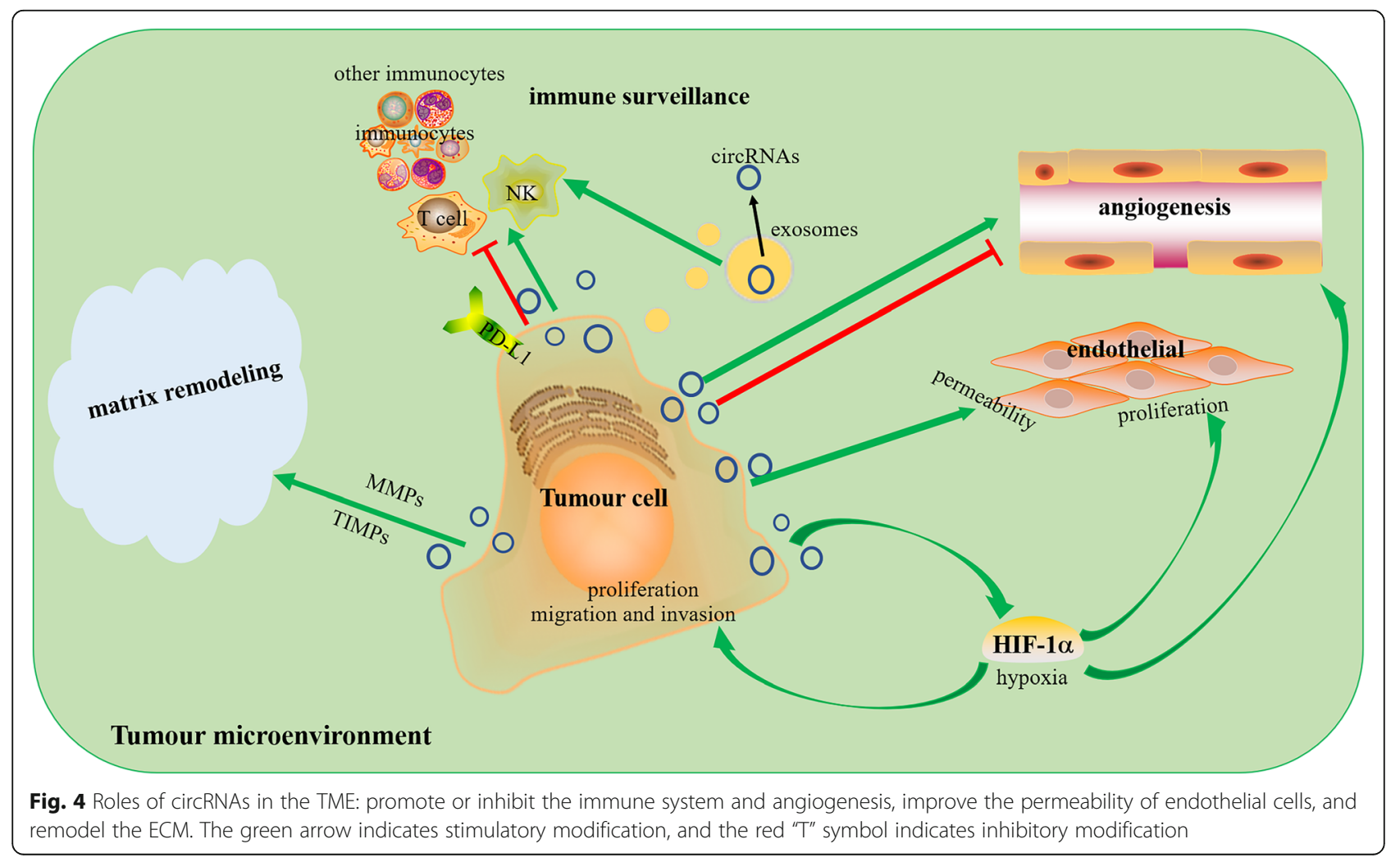


enormous potential and unsolved problems of circular RNAs as potential biomarkers and therapeutic targets in clinical applications. We are convinced that circulating circRNAs might be used as liquid biopsies and noninvasive biomarkers for the early detection, diagnosis, and treatment of cancer in the future.

\section{Abbreviations}

AR: androgen receptor; CircRNAs: Circular RNAs; CAFs: Cancer associated fibroblasts; CSC: Cancer stem cells; CRCCs: Colorectal cancer cells; CRC: Colorectal cancer; COL1A1: Collagen type I alpha 1 chain; DFS: Disease free survival; ECM: Extracellular matrix; EGFR: Epidermal growth factor receptor; EVs: Etracellular vesicles; EMT: Epithelial-mesenchymal transition; FDA: US Food and Drug Administration; GBM: Glioblastoma; GECs: Gliomaassociated endothelial cells; HCC: Hepatocellular carcinoma; HUVECs: Human umbilical vein endothelial cells; HIFs: Hypoxia inducible factors; HREs: Hypoxia-responsive elements; HPSE: Heparanase; LncRNAs: Long ncRNAs; LSCC: Laryngeal squamous cell carcinoma; MiRNAs: MicroRNAs; MDSCs: Myeloid-derived suppressor cells; MREs: MicroRNA response elements; MMPs: Matrix metalloproteinases; ncRNAs: Noncoding RNAs; NK: Natural killer; NSCLC: Non-small-cell lung carcinoma; OS: Osteosarcoma; OS: Overall survival; PD-1: Programmed death 1: PD-L1: Programmed deathligand 1; PC: Pancreatic cancer; PDAC: Pancreatic ductal adenocarcinoma; RBP: RNA-binding protein; SRSF1: Splicing factor Serine and Arginine rich splicing factor; SRY: Sex determining region Y; TME: Tumour microenvironment; Treg: Regulatory T cells; TAMs: Tumour associated macrophages; TILs: Tumour-infiltrating lymphocytes; TNBC: Triple-negative breast cancer; TICs: Tumour-initiating cells; TIMPs: Tissue inhibitors of metalloproteinases; TEXs: Tumour-related exosomes; USP7: Ubiquitin-specific protease 7; VEGFA: Vascular endothelial growth factor A; VM: Vasculogenic mimicry

\section{Acknowledgements}

This study was supported by The National Natural Science Foundation of China (81560385), The Medical Scientific and Technological Research Project of Henan Province (201702027), Youth Innovation Fund Project of The First Affiliated Hospital of Zhengzhou University (YNQN2017035), The China Postdoctoral Science Foundation (2017M610462, 2019T120648), The National Natural Science Foundation of Henan Province (182300410342) and The Health Commission Technology Talents Overseas Training Project of Henan Province (2018140).

\section{Author's contributions}

ZQS, LXL and JBL provided direction and quidance throughout the preparation of this manuscript. QGZ wrote and edited the manuscript. WWW and $\mathrm{QBZ}$ reviewed and made significant revisions to the manuscript. CC and WTY collected and prepared the related papers. All authors read and approved the final manuscript.

\section{Availability of data and materials \\ Not applicable.}

\section{Ethics approval and consent to participate}

Not applicable.

\section{Consent for publication}

Not applicable.

\section{Competing interests}

The authors declare that they have no competing interests.

\section{Author details}

'Department of Colorectal Surgery, The First Affiliated Hospital of Zhengzhou University, Zhengzhou 450052, China. ${ }^{2}$ Department of Geriatric Medicine, The First Affiliated Hospital of Zhengzhou University, Zhengzhou 450052, China. ${ }^{3}$ Academy of Medical Sciences, Zhengzhou University, Zhengzhou 450052, China. ${ }^{4}$ Department of Pathology, The First Affiliated Hospital, Zhengzhou University, Zhengzhou 450052, China.
Received: 5 July 2019 Accepted: 26 December 2019

Published online: 23 January 2020

\section{References}

1. Zhang QY, Wang FX, Jia KK, Kong LD. Natural Product Interventions for Chemotherapy and Radiotherapy-Induced Side Effects. Front Pharmacol. 2018:9:1253. https://doi.org/10.3389/fphar.2018.01253.

2. Hanahan D, Coussens LM. Accessories to the crime: functions of cells recruited to the tumor microenvironment. Cancer Cell. 2012:21(3):309-22. https://doi.org/10.1016/j.ccr.2012.02.022.

3. Balkwill FR, Capasso M, Hagemann T. The tumor microenvironment at a glance. J Cell Sci. 2012;125(Pt 23):5591-6. https://doi.org/10.1242/jcs.116392.

4. Hu M, Polyak K. Microenvironmental regulation of cancer development. Curr Opin Genet Dev. 2008;18(1):27-34. https://doi.org/10.1016/j.gde.2007.12.006.

5. Chen Y, Liu X, Yuan H, Yang Z, von Roemeling CA, Qie Y, et al. Therapeutic Remodeling of the Tumor Microenvironment Enhances Nanoparticle Delivery. Adv Sci (Weinh). 2019;6(5):1802070. https://doi.org/10.1002/advs. 201802070

6. Ocana MC, Martinez-Poveda B, Quesada AR, Medina MA. Metabolism within the tumor microenvironment and its implication on cancer progression: An ongoing therapeutic target. Med Res Rev. 2019;39(1):70-113. https://doi.org/ $10.1002 /$ med.21511.

7. He Y, Liu S, Mattei J, Bunn PA Jr, Zhou C, Chan D. The combination of antiKIR monoclonal antibodies with anti-PD-1/PD-L1 monoclonal antibodies could be a critical breakthrough in overcoming tumor immune escape in NSCLC. Drug Des Devel Ther. 2018:12:981-6. https://doi.org/10.2147/dddt. S163304.

8. Hameed S, Bhattarai P, Dai Z. Nanotherapeutic approaches targeting angiogenesis and immune dysfunction in tumor microenvironment. Sci China Life Sci. 2018;61(4):380-91. https://doi.org/10.1007/s11427-017-9256-1.

9. Patel A, Sant S. Hypoxic tumor microenvironment: Opportunities to develop targeted therapies. Biotechnol Adv. 2016;34(5):803-12. https://doi.org/10. 1016/j.biotechadv.2016.04.005.

10. Bronisz A, Godlewski J, Wallace JA, Merchant AS, Nowicki MO, Mathsyaraja $\mathrm{H}$, et al. Reprogramming of the tumour microenvironment by stromal PTENregulated miR-320. Nat Cell Biol. 2011;14(2):159-67. https://doi.org/10.1038/ ncb2396.

11. Aprelikova O, Yu X, Palla J, Wei BR, John S, Yi M, et al. The role of miR-31 and its target gene SATB2 in cancer-associated fibroblasts. Cell Cycle. 2010; 9(21):4387-98. https://doi.org/10.4161/cc.9.21.13674.

12. Chou J, Shahi P, Werb Z. microRNA-mediated regulation of the tumor microenvironment. Cell Cycle. 2013;12(20):3262-71. https://doi.org/10.4161/ cc.26087.

13. Wu K, Zhao Z, Liu K, Zhang J, Li G, Wang L. Long noncoding RNA Inc-sox 5 modulates CRC tumorigenesis by unbalancing tumor microenvironment. Cell Cycle. 2017:16(13):1295-301. https://doi.org/10.1080/15384101.2017.1317416.

14. Lin YH, Wu MH, Yeh CT, Lin KH. Long Non-Coding RNAs as Mediators of Tumor Microenvironment and Liver Cancer Cell Communication. Int J Mol Sci. Int J Mol Sci. 2018;19(12):3742. https://doi.org/10.3390/ijms19123742.

15. Sun Z, Yang S, Zhou Q, Wang G, Song J, Li Z, et al. Emerging role of exosome-derived long non-coding RNAs in tumor microenvironment. Mol Cancer. 2018;17(1):82. https://doi.org/10.1186/s12943-018-0831-z.

16. Chen LL, Yang L. Regulation of circRNA biogenesis. RNA Biol. 2015;12(4): 381-8. https://doi.org/10.1080/15476286.2015.1020271

17. Chen B, Huang S. Circular RNA: An emerging non-coding RNA as a regulator and biomarker in cancer. Cancer Lett 2018; 418: 41-50.doi:https:// doi.org/10.1016/j.canlet.2018.01.011.

18. Li Z, Zhou Y, Yang G, He S, Qiu X, Zhang L, et al. Using circular RNA SMARCA5 as a potential novel biomarker for hepatocellular carcinoma. Clin Chim Acta. 2019;492:37-44. https://doi.org/10.1016/j.cca.2019.02.001.

19. Su H, Zou D, Sun Y, Dai Y. Hypoxia-associated circDENND2A promotes glioma aggressiveness by sponging miR-625-5p. Cell Mol Biol Lett. 2019;24: 24. https://doi.org/10.1186/s11658-019-0149-X.

20. He Q, Zhao L, Liu Y, Liu X, Zheng J, Yu H, et al. circ-SHKBP1 Regulates the Angiogenesis of U87 Glioma-Exposed Endothelial Cells through miR-544a/ FOXP1 and miR-379/FOXP2 Pathways. Mol Ther Nucleic Acids. 2018:10:33148. https://doi.org/10.1016/j.omtn.2017.12.014

21. Paget $\mathrm{S}$. The distribution of secondary growths in cancer of the breast. 1889. Cancer Metastasis Rev. 1989;8(2):98-101.

22. Mendoza M, Khanna C. Revisiting the seed and soil in cancer metastasis. Int Biochem Cell Biol. 2009:41(7):1452-62. https://doi.org/10.1016/j.biocel.2009.01.015. 
23. Chen F, Zhuang X, Lin L, Yu P, Wang Y, Shi Y, et al. New horizons in tumor microenvironment biology: challenges and opportunities. BMC Med. 2015;13:45 https://doi.org/10.1186/s12916-015-0278-7.

24. Yuan $Y$, Jiang $Y C$, Sun $C K$, Chen $Q M$. Role of the tumor microenvironment in tumor progression and the clinical applications (Review). Oncol Rep. 2016;35(5):2499-515. https:/doi.org/10.3892/or.2016.4660.

25. Luo Z, Wang Q, Lau WB, Lau B, Xu L, Zhao L, et al. Tumor microenvironment: The culprit for ovarian cancer metastasis? Cancer Lett. 2016;377(2):174-82. https:/doi.org/ 10.1016/j.canlet.2016.04.038

26. Martin M, Wei $H$, Lu T. Targeting microenvironment in cancer therapeutics. Oncotarget. 2016;7(32):52575-83. https://doi.org/10.18632/ oncotarget.9824.

27. Junttila MR, de Sauvage FJ. Influence of tumour micro-environment heterogeneity on therapeutic response. Nature. 2013;501(7467):346-54. https://doi.org/10.1038/ nature12626.

28. Motz GT, Coukos $\mathrm{G}$. The parallel lives of angiogenesis and immunosuppression: cancer and other tales. Nat Rev Immunol. 2011;11(10):702-11. https:/doi.org/10. 1038/nri3064.

29. Altorki NK, Markowitz GJ, Gao D, Port JL, Saxena A, Stiles B, et al. The lung microenvironment: an important regulator of tumour growth and metastasis. Nat Rev Cancer. 2019;19(1):9-31. https://doi.org/10.1038/s41568-018-0081-9.

30. Danan M, Schwartz S, Edelheit S, Sorek R. Transcriptome-wide discovery of circular RNAs in Archaea. Nucleic Acids Res. 2012;40(7):3131-42. https:/doi.org/10.1093/nar/ gkr1009.

31. Ye CY, Chen L, Liu C, Zhu QH, Fan L. Widespread noncoding circular RNAs in plants. New Phytol. 2015;208(1):88-95. https://doi.org/10.1111/nph.13585.

32. Lu T, Cui L, Zhou Y, Zhu C, Fan D, Gong H, et al. Transcriptome-wide investigation of circular RNAs in rice. Rna. 2015;21(12):2076-87. https://doi. org/10.1261/rna.052282.115.

33. Fan X, Zhang X, Wu X, Guo H, Hu Y, Tang F, et al. Single-cell RNA-seq transcriptome analysis of linear and circular RNAs in mouse preimplantation embryos. Genome Biol. 2015;16:148. https://doi.org/10.1186/s13059-015-0706-1.

34. Shen $Y$, Guo $X$, Wang W. Identification and characterization of circular RNAs in zebrafish. FEBS Lett. 2017;591(1):213-20. https://doi.org/10.1002/1873-3468.12500.

35. Wang PL, Bao Y, Yee MC, Barrett SP, Hogan GJ, Olsen MN, et al. Circular RNA is expressed across the eukaryotic tree of life. PLoS One. 2014;9(6):e90859. https://doi.org/10.1371/journal.pone.0090859.

36. Rybak-Wolf A, Stottmeister C, Glazar P, Jens M, Pino N, Giusti S, et al. Circular RNAs in the Mammalian Brain Are Highly Abundant, Conserved, and Dynamically Expressed. Mol Cell. 2015;58(5):870-85. https://doi.org/ 10.1016/j.molcel.2015.03.027.

37. Jeck WR, Sorrentino JA, Wang K, Slevin MK, Burd CE, Liu J, et al. Circular RNAs are abundant, conserved, and associated with ALU repeats. Rna. 2013; 19(2):141-57. https://doi.org/10.1261/rna.035667.112.

38. Salzman J, Gawad C, Wang PL, Lacayo N, Brown PO. Circular RNAs are the predominant transcript isoform from hundreds of human genes in diverse cell types. PLoS One. 2012;7(2):e30733. https://doi.org/10.1371/journal.pone. 0030733.

39. Li X, Yang L, Chen LL. The Biogenesis, Functions, and Challenges of Circular RNAs. Mol Cell. 2018;71(3):428-42. https://doi.org/10.1016/j.molcel.2018.06.034.

40. Dong R, Ma XK, Chen LL, Yang L. Increased complexity of circRNA expression during species evolution. RNA Biol. 2017;14(8):1064-74. https://doi.org/10.1080/15476286.2016.1269999.

41. Salzman J, Chen RE, Olsen MN, Wang PL, Brown PO. Cell-type specific features of circular RNA expression. PLoS Genet. 2013;9(9):e1003777. https:// doi.org/10.1371/journal.pgen.1003777.

42. Nicolet BP, Engels S, Aglialoro F, van den Akker E, von Lindern M, Wolkers MC. Circular RNA expression in human hematopoietic cells is widespread and cell-type specific. Nucleic Acids Res. 2018;46(16):816880. https://doi.org/10.1093/nar/gky721.

43. Zhang P, Zuo Z, Shang W, Wu A, Bi R, Wu J, et al. Identification of differentially expressed circular RNAs in human colorectal cancer. Tumour Biol. 2017;39(3):1010428317694546. https://doi.org/10.1177/ 1010428317694546.

44. Westholm JO, Miura P, Olson S, Shenker S, Joseph B, Sanfilippo P, et al. Genome-wide analysis of drosophila circular RNAs reveals their structural and sequence properties and age-dependent neural accumulation. Cell Rep. 2014;9(5):1966-80. https://doi.org/10.1016/j.celrep.2014.10.062.

45. Zheng XB, Zhang $M, X u M Q$. Detection and characterization of ciRS-7: a potential promoter of the development of cancer. Neoplasma. 2017:64(3): 321-8. https://doi.org/10.4149/neo_2017_301.
46. Wang R, Zhang S, Chen X, Li N, Li J, Jia R, et al. CircNT5E Acts as a Sponge of miR-422a to Promote Glioblastoma Tumorigenesis. Cancer Res. 2018; 78(17):4812-25. https://doi.org/10.1158/0008-5472.Can-18-0532.

47. Wu J, Jiang Z, Chen C, Hu Q, Fu Z, Chen J, et al. CirclRAK3 sponges miR3607 to facilitate breast cancer metastasis. Cancer Lett. 2018;430:179-92. https://doi.org/10.1016/j.canlet.2018.05.033.

48. Hansen TB, Kjems J, Damgaard CK. Circular RNA and miR-7 in cancer. Cancer Res. 2013;73(18):5609-12. https://doi.org/10.1158/0008-5472.Can-131568.

49. Wang $K$, Sun $Y$, Tao W, Fei X, Chang C. Androgen receptor (AR) promotes clear cell renal cell carcinoma (ccRCC) migration and invasion via altering the circHIAT1/miR-195-5p/29a-3p/29c-3p/CDC42 signals. Cancer Lett. 2017;394:1-12. https://doi.org/10.1016/j.canlet.2016.12.036.

50. Conn SJ, Pillman KA, Toubia J, Conn VM, Salmanidis M, Phillips CA, et al. The RNA binding protein quaking regulates formation of circRNAs. Cell. 2015;160(6):1125-34. https://doi.org/10.1016/j.cell.2015.02.014.

51. Abdelmohsen K, Panda AC, Munk R, Grammatikakis I, Dudekula DB, De S, et al. Identification of HuR target circular RNAs uncovers suppression of PABPN1 translation by CircPABPN1. RNA Biol. 2017;14(3):361-9. https:/doi.org/10.1080/ 15476286.2017.1279788.

52. Yang ZG, Awan FM, Du WW, Zeng Y, Lyu J. Wu, et al. The Circular RNA Interacts with STAT3, Increasing Its Nuclear Translocation and Wound Repair by Modulating Dnmt3a and miR-17 Function. Mol Ther. 2017; 25(9):2062-74. https://doi.org/10.1016/j.ymthe.2017.05.022.

53. Zang J, Lu D, Xu A. The interaction of circRNAs and RNA binding proteins: An important part of circRNA maintenance and function. J Neurosci Res. 2018. https://doi.org/10.1002/jnr.24356.

54. Du WW, Yang W, Chen Y, Wu ZK, Foster FS, Yang Z, et al. Foxo3 circular RNA promotes cardiac senescence by modulating multiple factors associated with stress and senescence responses. Eur Heart J. 2017;38(18): 1402-12. https://doi.org/10.1093/eurheartj/ehw001.

55. Du WW, Fang L, Yang W, Wu N, Awan FM, Yang Z, et al. Induction of tumor apoptosis through a circular RNA enhancing Foxo3 activity. Cell Death Differ. 2017;24(2):357-70. https://doi.org/10.1038/cdd.2016.133.

56. Du WW, Yang W, Liu E, Yang Z, Dhaliwal P, Yang BB. Foxo3 circular RNA retards cell cycle progression via forming ternary complexes with p21 and CDK2. Nucleic Acids Res. 2016;44(6):2846-58. https://doi.org/10.1093/nar/ gkw027.

57. Zheng X, Chen L, Zhou Y, Wang Q, Zheng Z, Xu B, et al. A novel protein encoded by a circular RNA circPPP1R12A promotes tumor pathogenesis and metastasis of colon cancer via Hippo-YAP signaling. Mol Cancer. 2019; 18(1):47. https://doi.org/10.1186/s12943-019-1010-6.

58. Ye L, Zhang Q, Cheng Y, Chen X, Wang G, Shi M, et al. Tumor-derived exosomal HMGB1 fosters hepatocellular carcinoma immune evasion by promoting TIM-1(+) regulatory B cell expansion. J Immunother Cancer. 2018;6(1):145. https://doi.org/10.1186/s40425-018-0451-6.

59. Zhang $Y$, Zhang $X O$, Chen $T$, Xiang JF, Yin QF, Xing YH, et al. Circular intronic long noncoding RNAs. Mol Cell. 2013;51(6):792-806. https://doi.org/ 10.1016/j.molcel.2013.08.017.

60. Yang Q, Du WW, Wu N, Yang W, Awan FM, Fang L, et al. A circular RNA promotes tumorigenesis by inducing c-myc nuclear translocation. Cell Death Differ. 2017;24(9):1609-20. https://doi.org/10.1038/cdd.2017.86.

61. Bach DH, Lee SK, Sood AK. Circular RNAs in Cancer. Mol Ther Nucleic Acids. 2019;16:118-29. https://doi.org/10.1016/j.omtn.2019.02.005.

62. Dunn GP, Old LJ, Schreiber RD. The immunobiology of cancer immunosurveillance and immunoediting. Immunity. 2004;21(2):137-48. https://doi.org/10.1016/j.immuni.2004.07.017.

63. Hanahan D, Weinberg RA. Hallmarks of cancer: the next generation. Cell. 2011;144(5):646-74. https://doi.org/10.1016/j.cell.2011.02.013.

64. Schreiber RD, Old LJ, Smyth MJ. Cancer immunoediting: integrating immunity's roles in cancer suppression and promotion. Science. 2011; 331(6024):1565-70. https://doi.org/10.1126/science.1203486.

65. Chen YG, Kim MV, Chen X, Batista PJ, Aoyama S, Wilusz JE, et al. Sensing Self and Foreign Circular RNAs by Intron Identity. Mol Cell. 2017;67(2):228-238. e225. https://doi.org/10.1016/j.molcel.2017.05.022.

66. Barbalat R, Ewald SE, Mouchess ML, Barton GM. Nucleic acid recognition by the innate immune system. Annu Rev Immunol. 2011;29:185-214. https:// doi.org/10.1146/annurev-immunol-031210-101340.

67. Wu J, Chen ZJ. Innate immune sensing and signaling of cytosolic nucleic acids. Annu Rev Immunol. 2014;32:461-88. https:/doi.org/10.1146/annurev-immunol032713-120156. 
68. Iurescia S, Fioretti D, Rinaldi M. Nucleic Acid Sensing Machinery: Targeting Innate Immune System for Cancer Therapy. Recent Pat Anticancer Drug Discov. 2018;13(1): 2-17. https:/doi.org/10.2174/1574892812666171030163804.

69. Bourquin C, Pommier A, Hotz C. Harnessing the immune system to fight cancer with Toll-like receptor and RIG--like receptor agonists. Pharmacol Res. 2019;104192. https:/doi.org/10.1016/j.phrs.2019.03.001.

70. Maybruck BT, Pfannenstiel LW, Diaz-Montero M, Gastman BR. Tumor-derived exosomes induce CD8(+) T cell suppressors. J Immunother Cancer. 2017;5(1):65. https:/doi.org/10.1186/s40425-017-0269-7.

71. Ning Y, Shen K, Wu Q, Sun X, Bai Y, Xie Y, et al. Tumor exosomes block dendritic cells maturation to decrease the T cell immune response. Immunol Lett. 2018;199: 36-43. https://doi.org/10.1016/j.imlet.2018.05.002

72. Li P, Liu C, Yu Z, Wu M. New Insights into Regulatory T Cells: Exosome- and NonCoding RNA-Mediated Regulation of Homeostasis and Resident Treg Cells. Front Immunol. 2016;7:574. https:/doi.org/10.3389/fimmu.2016.00574.

73. Valadi H, Ekstrom K, Bossios A, Sjostrand M, Lee JJ, Lotvall JO. Exosome-mediated transfer of mRNAs and microRNAs is a novel mechanism of genetic exchange between cells. Nat Cell Biol. 2007;9(6):654-9. https://doi.org/10.1038/ncb1596.

74. Dai X, Chen C, Yang Q, Xue J, Chen X, Sun B, et al. Exosomal circRNA_100284 from arsenite-transformed cells, via microRNA-217 regulation of EZH2, is involved in the malignant transformation of human hepatic cells by accelerating the cell cycle and promoting cell proliferation. Cell Death Dis. 2018;9(5):454. https://doi.org/10.1038/ s41419-018-0485-1.

75. Dou Y, Cha DJ, Franklin JL, Higginbotham JN, Jeppesen DK, Weaver AM, et al. Circular RNAs are down-regulated in KRAS mutant colon cancer cells and can be transferred to exosomes. Sci Rep. 2016;6:37982. https://doi.org/10.1038/srep37982.

76. Lasda E, Parker R. Circular RNAs Co-Precipitate with Extracellular Vesicles: A Possible Mechanism for circRNA Clearance. PLoS One. 2016;11(2):e0148407. https:/doi.org/10. 1371/journal.pone.0148407.

77. Weng Q, Chen M, Li M, Zheng YF, Shao G, Fan W, et al. Global microarray profiling identified hsa_circ_0064428 as a potential immune-associated prognosis biomarker for hepatocellular carcinoma. J Med Genet. 2019;56(1):32-8. https:/doi.org/10.1136/ jmedgenet-2018-105440.

78. Keir ME, Butte MJ, Freeman GJ, Sharpe AH. PD-1 and its ligands in tolerance and immunity. Annu Rev Immunol. 2008;26:677-704. https:/doi.org/10.1146/annurev. immunol.26.021607.090331.

79. Zhang XL, Xu LL, Wang F. Hsa_circ_0020397 regulates colorectal cancer cell viability, apoptosis and invasion by promoting the expression of the miR-138 targets TERT and PD-L1. Cell Biol Int. 2017;41(9):1056-64. https://doi.org/10.1002/cbin.10826.

80. Shi MH, Xing YF, Zhang ZL, Huang JA, Chen YJ. Effect of soluble PD-L1 released by lung cancer cells in regulating the function of $T$ lymphocytes. Zhonghua Zhong Liu Za Zhi. 2013;35(2):85-8. https://doi.org/10.3760/cma.j. issn.0253-3766.2013.02.002

81. Xu C, Fillmore CM, Koyama S, Wu H, Zhao Y, Chen Z, et al. Loss of Lkb1 and Pten leads to lung squamous cell carcinoma with elevated PD-L1 expression. Cancer Cell. 2014;25(5):590-604. https://doi.org/10.1016/j.ccr. 2014.03.033.

82. Gevensleben H, Dietrich D, Golletz C, Steiner S, Jung M, Thiesler T, et al. The Immune Checkpoint Regulator PD-L1 Is Highly Expressed in Aggressive Primary Prostate Cancer. Clin Cancer Res. 2016;22(8):1969-77. https://doi org/10.1158/1078-0432.Ccr-15-2042

83. Passardi A, Canale M, Valgiusti M, Ulivi P. Immune Checkpoints as a Target for Colorectal Cancer Treatment. Int J Mol Sci. 2017;18(6). https://doi.org/10. 3390/ijms18061324.

84. Hui R, Garon EB, Goldman JW, Leighl NB, Hellmann MD, Patnaik A, et al. Pembrolizumab as first-line therapy for patients with PD-L1-positive advanced non-small cell lung cancer: a phase 1 trial. Ann Oncol. 2017;28(4): 874-81. https://doi.org/10.1093/annonc/mdx008.

85. McCall NS, Dicker AP, Lu B. Beyond Concurrent Chemoradiation: The Emerging Role of PD-1/PD-L1 Inhibitors in Stage III Lung Cancer. Clin Cancer Res. 2018;24(6):1271-6. https://doi.org/10.1158/1078-0432.Ccr-17-3269.

86. Sonpavde G. PD-1 and PD-L1 Inhibitors as Salvage Therapy for Urothelial Carcinoma. N Engl J Med. 2017;376(11):1073-4. https://doi.org/10.1056/ NEJMe1701182.

87. Li D, Wang X, Yang M, Kan Q, Duan Z. miR3609 sensitizes breast cancer cells to adriamycin by blocking the programmed death-ligand 1 immune checkpoint. Exp Cell Res. 2019;380(1):20-8. https://doi.org/10.1016/j.yexcr. 2019.03.025

88. Xie WB, Liang LH, Wu KG, Wang LX, He X, Song C, et al. MiR-140 Expression Regulates Cell Proliferation and Targets PD-L1 in NSCLC. Cell Physio Biochem. 2018;46(2):654-63. https://doi.org/10.1159/000488634.
89. Kim R, Emi M, Tanabe K. Cancer immunoediting from immune surveillance to immune escape. Immunology. 2007;121(1):1-14. https://doi.org/10.1111/j. 1365-2567.2007.02587.x.

90. Wang WT, Zhu HY, Wu YJ, Xia Y, Wu JZ, Wu W, et al. Elevated absolute NK cell counts in peripheral blood predict good prognosis in chronic lymphocytic leukemia. J Cancer Res Clin Oncol. 2018;144(3):449-57. https:// doi.org/10.1007/s00432-017-2568-2.

91. Xu B, Chen L, Li J, Zheng X, Shi L, Wu C, et al. Prognostic value of tumor infiltrating NK cells and macrophages in stage II+III esophageal cancer patients. Oncotarget. 2016;7(46):74904-16. https://doi.org/10.18632/ oncotarget.12484

92. Ma Y, Zhang C, Zhang B, Yu H, Yu Q. circRNA of AR-suppressed PABPC1 91 bp enhances the cytotoxicity of natural killer cells against hepatocellular carcinoma via upregulating UL16 binding protein 1. Oncol Lett. 2019;17(1): 388-97. https://doi.org/10.3892/ol.2018.9606.

93. Ou ZL, Luo Z, Wei W, Liang S, Gao TL, Lu YB. Hypoxia-induced shedding of MICA and HIF1A-mediated immune escape of pancreatic cancer cells from NK cells: role of circ_0000977/miR-153 axis. RNA Biol. 2019:1-12. https://doi. org/10.1080/15476286.2019.1649585.

94. Viallard C, Larrivee B. Tumor angiogenesis and vascular normalization: alternative therapeutic targets. Angiogenesis. 2017;20(4):409-26. https://doi. org/10.1007/s10456-017-9562-9

95. Marusyk A, Polyak K. Tumor heterogeneity: causes and consequences. Biochim Biophys Acta. 2010;1805(1):105-17. https://doi.org/10.1016/j.bbcan. 2009.11.002.

96. Li J, Li H, Lv X, Yang Z, Gao M, Bi Y, et al. Diagnostic performance of circular RNAs in human cancers: A systematic review and meta-analysis. Mol Genet Genomic Med. 2019:e749. https://doi.org/10.1002/mgg3.749.

97. Zhong Z, Huang M, Lv M, He Y, Duan C, Zhang L, et al. Circular RNA MYLK as a competing endogenous RNA promotes bladder cancer progression through modulating VEGFANEGFR2 signaling pathway. Cancer Lett. 2017; 403:305-17. https://doi.org/10.1016/j.canlet.2017.06.027.

98. Claesson-Welsh L, Welsh M. VEGFA and tumour angiogenesis. J Intern Med. 2013;273(2):114-27. https://doi.org/10.1111/joim.12019.

99. Cao W, Zhao Y, Wang L, Huang X. Circ0001429 regulates progression of bladder cancer through binding miR-205-5p and promoting VEGFA expression. Cancer Biomark. 2019;25(1):101-13. https://doi.org/10.3233/cbm-182380.

100. Meng Q, Li S, Liu Y, Zhang S, Jin J, Zhang Y, et al. Circular RNA circSCAF11 Accelerates the Glioma Tumorigenesis through the miR-421/SP1/NEGFA Axis. Mol Ther Nucleic Acids. 2019;17:669-77. https://doi.org/10.1016/j.omtn. 2019.06.022.

101. Yang P, Qiu Z, Jiang Y, Dong L, Yang W, Gu C, et al. Silencing of cZNF292 circular RNA suppresses human glioma tube formation via the Wnt/betacatenin signaling pathway. Oncotarget. 2016;7(39):63449-55. https://doi.org/ 10.18632/oncotarget.11523.

102. Boeckel JN, Jae N, Heumuller AW, Chen W, Boon RA, Stellos K, et al. Identification and Characterization of Hypoxia-Regulated Endothelial Circular RNA. Circ Res. 2015;117(10):884-90. https://doi.org/10.1161/circresaha.115. 306319

103. Yang W, Liu Y, Gao R, Xiu Z, Sun T. Knockdown of cZNF292 suppressed hypoxic human hepatoma SMMC7721 cell proliferation, vasculogenic mimicry, and radioresistance. Cell Signal. 2019;60:122-35. https://doi.org/10. 1016/j.cellsig.2019.04.011.

104. Dang RY, Liu FL, Li Y. Circular RNA hsa_circ_0010729 regulates vascular endothelial cell proliferation and apoptosis by targeting the miR-186/HIF1 alpha axis. Biochem Biophys Res Commun. 2017;490(2):104-10. https://doi. org/10.1016/j.bbrc.2017.05.164.

105. He Z, Ruan X, Liu X, Zheng J, Liu Y, Liu L, et al. FUS/circ_002136/miR-138$5 \mathrm{p} / \mathrm{SOX} 13$ feedback loop regulates angiogenesis in Glioma. J Exp Clin Cancer Res. 2019;38(1):65. https://doi.org/10.1186/s13046-019-1065-7.

106. He Q, Zhao L, Liu X, Zheng J, Liu Y, Liu L, et al. MOV10 binding circ-DICER1 regulates the angiogenesis of glioma via miR-103a-3p/miR-382-5p mediated ZIC4 expression change. J Exp Clin Cancer Res. 2019;38(1):9. https://doi.org/ 10.1186/s13046-018-0990-1.

107. Li Y, Zheng F, Xiao X, Xie F, Tao D, Huang C, et al. CircHIPK3 sponges miR558 to suppress heparanase expression in bladder cancer cells. EMBO Rep. 2017;18(9):1646-59. https://doi.org/10.15252/embr.201643581.

108. Barbagallo D, Caponnetto A, Brex D, Mirabella F, Barbagallo C, Lauretta G, et al. CircSMARCA5 Regulates VEGFA mRNA Splicing and Angiogenesis in Glioblastoma Multiforme Through the Binding of SRSF1. Cancers (Basel). 2019;11(2). https://doi. org/10.3390/cancers11020194. 
109. Gilbert MR, Dignam JJ, Armstrong TS, Wefel JS, Blumenthal DT, Vogelbaum MA, et al. A randomized trial of bevacizumab for newly diagnosed glioblastoma. N Engl J Med. 2014;370(8):699-708. https:/doi.org/10.1056/NEJMoa1308573.

110. Li CY, Ma L, Yu B. Circular RNA hsa_circ_0003575 regulates oxLDL induced vascular endothelial cells proliferation and angiogenesis. Biomed Pharmacother. 2017;95: 1514-9. https:/doi.org/10.1016/j.biopha.2017.09.064

111. Chouaib S, Kieda C, Benlalam H, Noman MZ, Mami-Chouaib F, Ruegg C. Endothelial cells as key determinants of the tumor microenvironment: interaction with tumor cells, extracellular matrix and immune killer cells. Crit Rev Immunol. 2010;30(6):529-45.

112. Li J, Li Z, Jiang P, Peng M, Zhang X, Chen $K$, et al. Circular RNA IARS (circ-IARS) secreted by pancreatic cancer cells and located within exosomes regulates endothelial monolayer permeability to promote tumor metastasis. J Exp Clin Cancer Res. 2018;37(1):177. https://doi.org/10.1186/s13046-018-0822-3.

113. Li Y, Ye D. Cancer therapy by targeting hypoxia-inducible factor-1. Curr Cancer Drug Targets. 2010;10(7):782-96.

114. Huang $Y$, Lin D, Taniguchi CM. Hypoxia inducible factor (HIF) in the tumor microenvironment: friend or foe? Sci China Life Sci. 2017;60(10):1114-24. https:/doi. org/10.1007/s11427-017-9178-y.

115. Liang G, Liu Z, Tan L, Su AN, Jiang WG, Gong C. HIF1alpha-associated circDENND4C Promotes Proliferation of Breast Cancer Cells in Hypoxic Environment. Anticancer Res. 2017:37(8):4337-43. https:/doi.org/10.21873/anticanres.11827.

116. Ren S, Liu J, Feng Y, Li Z, He L, Li L, et al. Knockdown of circDENND4C inhibits glycolysis, migration and invasion by up-regulating miR-200b/c in breast cancer under hypoxia. J Exp Clin Cancer Res. 2019;38(1):388. https:// doi.org/10.1186/s13046-019-1398-2.

117. Theocharis AD, Skandalis SS, Gialeli C, Karamanos NK. Extracellular matrix structure. Adv Drug Deliv Rev. 2016;97:4-27. https://doi.org/10.1016/j.addr.2015.11.001.

118. Nelson AR, Fingleton B, Rothenberg ML, Matrisian LM. Matrix metalloproteinases: biologic activity and clinical implications. J Clin Oncol. 2000;18(5):1135-49. https:/doi. org/10.1200/jco.2000.18.5.1135.

119. Zhang H, Zhu L, Bai M, Liu Y, Zhan Y, Deng T, et al. Exosomal circRNA derived from gastric tumor promotes white adipose browning by targeting the miR-133/PRDM16 pathway. Int J Cancer. 2019;144(10):2501-15. https:// doi.org/10.1002/ijc.31977.

120. Li P, Chen H, Chen S, Mo X, Li T, Xiao B, et al. Circular RNA 0000096 affects cell growth and migration in gastric cancer. Br J Cancer. 2017;116(5):626-33. https:/doi. org/10.1038/bjc.2016.451

121. He C, Huang C, Zhou R, Yu H. CircLMNB1 promotes colorectal cancer by regulating cell proliferation, apoptosis and epithelial-mesenchymal transition. Onco Targets Ther. 2019;12:6349-59. https://doi.org/10.2147/ott. S204741.

122. Yang J, Cong X, Ren M, Sun H, Liu T, Chen G, et al. Circular RNA hsa circRNA_0007334 is Predicted to Promote MMP7 and COL1A1 Expression by Functioning as a miRNA Sponge in Pancreatic Ductal Adenocarcinoma. J Oncol. 2019:2019:7630894. https://doi.org/10.1155/2019/7630894.

123. Yamamoto K, Murphy G, Troeberg L. Extracellular regulation of metalloproteinases. Matrix Biol. 2015;44-46:255-63. https://doi.org/10.1016/j. matbio.2015.02.007.

124. Yu J, Xu QG, Wang ZG, Yang Y, Zhang L, Ma JZ, et al. Circular RNA CSMARCA5 inhibits growth and metastasis in hepatocellular carcinoma. J Hepatol. 2018;68(6):1214-27. https://doi.org/10.1016/j.jhep.2018.01.012.

125. Lee Y, El Andaloussi S, Wood MJ. Exosomes and microvesicles: extracellular vesicles for genetic information transfer and gene therapy. Hum Mol Genet. 2012;21(R1):R125-34. https://doi.org/10.1093/hmg/dds317.

126. Shao H, Im H, Castro CM, Breakefield X, Weissleder R, Lee H. New Technologies for Analysis of Extracellular Vesicles. Chem Rev. 2018;118(4): 1917-50. https://doi.org/10.1021/acs.chemrev.7b00534.

127. Balaj L, Lessard R, Dai L, Cho YJ, Pomeroy SL, Breakefield XO, et al. Tumour microvesicles contain retrotransposon elements and amplified oncogene sequences. Nat Commun. 2011;2:180. https://doi.org/10.1038/ncomms1180.

128. Kahlert C, Melo SA, Protopopov A, Tang J, Seth S, Koch M, et al. Identification of double-stranded genomic DNA spanning all chromosomes with mutated KRAS and p53 DNA in the serum exosomes of patients with pancreatic cancer. J Biol Chem. 2014;289(7):3869-75. https://doi.org/10.1074/ jbc. C113.532267.

129. Tetta C, Ghigo E, Silengo L, Deregibus MC, Camussi G. Extracellular vesicles as an emerging mechanism of cell-to-cell communication. Endocrine. 2013; 44(1):11-9. https://doi.org/10.1007/s12020-012-9839-0.

130. Yoshimura A, Sawada K, Nakamura K, Kinose Y, Nakatsuka E, Kobayashi M, et al. Exosomal miR-99a-5p is elevated in sera of ovarian cancer patients and promotes cancer cell invasion by increasing fibronectin and vitronectin expression in neighboring peritoneal mesothelial cells. BMC Cancer. 2018; 18(1):1065. https://doi.org/10.1186/s12885-018-4974-5.

131. Li Y, Zheng Q, Bao C, Li S, Guo W, Zhao J, et al. Circular RNA is enriched and stable in exosomes: a promising biomarker for cancer diagnosis. Cell Res. 2015;25(8):981-4. https://doi.org/10.1038/cr.2015.82.

132. Xu Z, Li P, Fan L, Wu M. The Potential Role of circRNA in Tumor Immunity Regulation and Immunotherapy. Front Immunol. 2018;9:9. https://doi.org/10. 3389/fimmu.2018.00009

133. Bai H, Lei K, Huang F, Jiang Z, Zhou X. Exo-circRNAs: a new paradigm for anticancer therapy. Mol Cancer. 2019;18(1):56. https://doi.org/10.1186/ s12943-019-0986-2.

134. Wang M, Zhao J, Zhang L, Wei F, Lian Y, Wu Y, et al. Role of tumor microenvironment in tumorigenesis. J Cancer. 2017;8(5):761-73. https://doi. org/10.7150/jca.17648.

135. Zhang H, Deng T, Ge S, Liu Y, Bai M, Zhu K, et al. Exosome circRNA secreted from adipocytes promotes the growth of hepatocellular carcinoma by targeting deubiquitination-related USP7. Oncogene. 2019;38(15):2844-59. https://doi.org/10.1038/s41388-018-0619-z.

136. Wang Z, Chen JQ, Liu JL, Tian L. Exosomes in tumor microenvironment: novel transporters and biomarkers. J Transl Med. 2016;14(1):297. https://doi. org/10.1186/s12967-016-1056-9.

137. Chen W, Jiang J, Xia W, Huang J. Tumor-Related Exosomes Contribute to Tumor-Promoting Microenvironment: An Immunological Perspective. J Immunol Res. 2017;2017:1073947. https://doi.org/10.1155/2017/1073947.

138. Roma-Rodrigues C, Raposo LR, Cabral R, Paradinha F, Baptista PV, Fernandes AR. Tumor Microenvironment Modulation via Gold Nanoparticles Targeting Malicious Exosomes: Implications for Cancer Diagnostics and Therapy. Int J Mol Sci. 2017;18(1). https://doi.org/10.3390/ijms18010162

139. McGee HM, Jiang D, Soto-Pantoja DR, Nevler A, Giaccia AJ, Woodward WA. Targeting the Tumor Microenvironment in Radiation Oncology: Proceedings from the 2018 ASTRO-AACR Research Workshop. Clin Cancer Res. 2019; 25(10):2969-74. https://doi.org/10.1158/1078-0432.Ccr-18-3781.

140. Lee CG, Heijn M, di Tomaso E, Griffon-Etienne G, Ancukiewicz M, Koike C, et al. Anti-Vascular endothelial growth factor treatment augments tumor radiation response under normoxic or hypoxic conditions. Cancer Res. 2000; 60(19):5565-70.

141. Moeller BJ, Dreher MR, Rabbani ZN, Schroeder T, Cao Y, Li CY, et al, Pleiotropic effects of HIF-1 blockade on tumor radiosensitivity. Cancer Cell. 2005;8(2):99-110. https://doi.org/10.1016/j.ccr.2005.06.016.

142. Karar J, Maity A. Modulating the tumor microenvironment to increase radiation responsiveness. Cancer Biol Ther. 2009;8(21):1994-2001. https://doi. org/10.4161/cbt.8.21.9988.

143. Chen T, Luo J, Gu Y, Huang J, Luo Q, Yang Y. Comprehensive analysis of circular RNA profiling in AZD9291-resistant non-small cell lung cancer cell lines. Thorac Cancer. 2019;10(4):930-41. https://doi.org/10.1111/1759-7714. 13032.

144. Xiong W, Ai YQ, Li YF, Ye Q, Chen ZT, Qin JY, et al. Microarray Analysis of Circular RNA Expression Profile Associated with 5-Fluorouracil-Based Chemoradiation Resistance in Colorectal Cancer Cells. Biomed Res Int. 2017; 2017:8421614. https://doi.org/10.1155/2017/8421614.

145. Shao F, Huang M, Meng F, Huang Q. Circular RNA Signature Predicts Gemcitabine Resistance of Pancreatic Ductal Adenocarcinoma. Front Pharmacol. 2018;9:584. https://doi.org/10.3389/fphar.2018.00584.

146. Sang Y, Chen B, Song X, Li Y, Liang Y, Han D, et al. circRNA_0025202 Regulates Tamoxifen Sensitivity and Tumor Progression via Regulating the miR-182-5p/FOXO3a Axis in Breast. Cancer. Mol Ther. 2019. https://doi.org/ 10.1016/j.ymthe.2019.05.011.

147. Su H, Lin F, Deng X, Shen L, Fang Y, Fei Z, et al. Profiling and bioinformatics analyses reveal differential circular RNA expression in radioresistant esophageal cancer cells. J Transl Med. 2016;14(1):225. https://doi.org/10. 1186/s12967-016-0977-7.

148. Horsman MR, Mortensen LS, Petersen JB, Busk M, Overgaard J. Imaging hypoxia to improve radiotherapy outcome. Nat Rev Clin Oncol. 2012;9(12): 674-87. https://doi.org/10.1038/nrclinonc.2012.171.

149. Ishii $H$, Iwatsuki M, leta $K$, Ohta D, Haraguchi $N$, Mimori $K$, et al. Cancer stem cells and chemoradiation resistance. Cancer Science. 2008:99(10):1871-7. https://doi.org/10.1111/j.1349-7006.2008.00914.x.

150. Cheng CC, Chao WT, Liao CC, Shih JH, Lai YS, Hsu YH, et al. The Roles Of Angiogenesis And Cancer Stem Cells In Sorafenib Drug Resistance In Hepatocellular Carcinoma. Oncotargets Therapy. 2019;12:8217-27. https:// doi.org/10.2147/Ott.S217468 
151. Mattern J. Role of angiogenesis in drug resistance. Anticancer Research. 2001;21(6b):4265-70

152. Wu Y, Zhang Y, Niu M, Shi Y, Liu H, Yang D, et al. Whole-Transcriptome Analysis of CD133+CD144+ Cancer Stem Cells Derived from Human Laryngeal Squamous Cell Carcinoma Cells. Cell Physiol Biochem. 2018;47(4): 1696-710. https://doi.org/10.1159/000490992.

153. Henry NL, Hayes DF. Cancer biomarkers. Mol Oncol. 2012;6(2):140-6. https:// doi.org/10.1016/j.molonc.2012.01.010.

154. Jafari GF. Circular RNA in Saliva. Adv Exp Med Biol. 2018;1087:131-9. https:// doi.org/10.1007/978-981-13-1426-1_11.

155. Lu R, Shao Y, Ye G, Xiao B, Guo J. Low expression of hsa_circ_0006633 in human gastric cancer and its clinical significances. Tumour Biol. 2017;39(6): 1010428317704175. https://doi.org/10.1177/1010428317704175.

156. Yin WB, Yan MG, Fang X, Guo JJ, Xiong W, Zhang RP. Circulating circular RNA hsa_circ_0001785 acts as a diagnostic biomarker for breast cancer detection. Clin Chim Acta. 2018;487:363-8. https://doi.org/10.1016/j.cca.2017. 10.011 .

157. Zhao Q, Chen S, Li T, Xiao B, Zhang X. Clinical values of circular RNA 0000181 in the screening of gastric cancer. J Clin Lab Anal. 2018;32(4): e22333. https://doi.org/10.1002/jcla.22333.

158. Chen S, Li T, Zhao Q, Xiao B, Guo J. Using circular RNA hsa_circ_0000190 as a new biomarker in the diagnosis of gastric cancer. Clin Chim Acta. 2017; 466:167-71. https://doi.org/10.1016/j.cca.2017.01.025.

159. Wang Q, Chen J, Wang A, Sun L, Qian L, Zhou X, et al. Differentially expressed circRNAs in melanocytes and melanoma cells and their effect on cell proliferation and invasion. Oncol Rep. 2018;39(4):1813-24. https://doi. org/10.3892/or.2018.6263.

160. Xu H, Wang C, Song H, Xu Y, Ji G. RNA-Seq profiling of circular RNAs in human colorectal Cancer liver metastasis and the potential biomarkers. Mol Cancer. 2019;18(1):8. https://doi.org/10.1186/s12943-018-0932-8.

161. Wang T, Wang X, Du Q, Wu N, Liu X, Chen Y, et al. The circRNA circP4HB promotes NSCLC aggressiveness and metastasis by sponging miR-133a-5p. Biochem Biophys Res Commun. 2019;513(4):904-11. https://doi.org/10.1016/ j.bbrc.2019.04.108.

162. Guo J, Duan H, Li Y, Yang L, Yuan L. A novel circular RNA circ-ZNF652 promotes hepatocellular carcinoma metastasis through inducing snailmediated epithelial-mesenchymal transition by sponging miR-203/miR-5025p. Biochem Biophys Res Commun. 2019;513(4):812-9. https://doi.org/10. 1016/j.bbrc.2019.03.214.

163. Jin P, Huang Y, Zhu P, Zou Y, Shao T, Wang O. CircRNA circHIPK3 serves as a prognostic marker to promote glioma progression by regulating miR-654/ IGF2BP3 signaling. Biochem Biophys Res Commun. 2018;503(3):1570-4. https://doi.org/10.1016/j.bbrc.2018.07.081.

164. Chen B, Wei W, Huang X, Xie X, Kong Y, Dai D, et al. circEPSTI1 as a Prognostic Marker and Mediator of Triple-Negative Breast Cancer Progression. Theranostics. 2018;8(14):4003-15. https://doi.org/10.7150/thno. 24106.

165. Tang $\mathrm{H}$, Huang $X$, Wang J, Yang L, Kong Y, Gao G, et al. circKIF4A acts as a prognostic factor and mediator to regulate the progression of triplenegative breast cancer. 2019;18(1):23-Mol Cancer. https://doi.org/10.1186/ s12943-019-0946-x.

166. Weng W, Wei Q, Toden S, Yoshida K, Nagasaka T, Fujiwara T, et al. Circular RNA ciRS-7-A Promising Prognostic Biomarker and a Potential Therapeutic Target in Colorectal Cancer. Clin Cancer Res. 2017;23(14):3918-28. https:// doi.org/10.1158/1078-0432.Ccr-16-2541.

167. Nie WB, Zhao LM, Guo R, Wang MX, Ye FG. Circular RNA circ-NT5C2 acts as a potential novel biomarker for prognosis of osteosarcoma. Eur Rev Med Pharmacol Sci. 2018;22(19):6239-44. https://doi.org/10.26355/eurrev_ 201810_16030.

168. Ou ZL, Luo Z, Wei W, Liang S, Gao TL, Lu YB. Hypoxia-induced shedding of MICA and HIF1A-mediated immune escape of pancreatic cancer cells from NK cells: role of circ_0000977/miR-153 axis. RNA Biol. 2019;16(11):1592-603. https://doi.org/10.1080/15476286.2019.1649585.

169. Su H. Hypoxia-associated circDENND2A promotes glioma aggressiveness by sponging miR-625-5p. 2019;24. https://doi.org/10.1186/s11658-019-0149-X.

\section{Publisher's Note}

Springer Nature remains neutral with regard to jurisdictional claims in published maps and institutional affiliations.

Ready to submit your research? Choose BMC and benefit from:

- fast, convenient online submission

- thorough peer review by experienced researchers in your field

- rapid publication on acceptance

- support for research data, including large and complex data types

- gold Open Access which fosters wider collaboration and increased citations

- maximum visibility for your research: over $100 \mathrm{M}$ website views per year

At BMC, research is always in progress.

Learn more biomedcentral.com/submissions 